\title{
A Novel TODIM with Probabilistic Hesitant Fuzzy Information and Its Application in Green Supplier Selection
}

\author{
Xiaoli Tian $\left(\mathbb{D},{ }^{1}\right.$ Meiling Niu, ${ }^{2}$ Jiangshui $\mathrm{Ma}^{1}{ }^{1}$ and Zeshui $\mathrm{Xu} \mathbb{D}^{3}$ \\ ${ }^{1}$ School of Business Administration, Southwestern University of Finance and Economics, Chengdu 611130, China \\ ${ }^{2}$ School of Public Finance and Taxation, Central University of Finance and Economics, Beijing 100081, China \\ ${ }^{3}$ Business School, Sichuan University, Chengdu 610064, China \\ Correspondence should be addressed to Zeshui Xu; xuzeshui@263.net
}

Received 3 August 2020; Revised 4 September 2020; Accepted 22 September 2020; Published 12 December 2020

Academic Editor: Thiago Christiano Silva

Copyright ( $\odot 2020$ Xiaoli Tian et al. This is an open access article distributed under the Creative Commons Attribution License, which permits unrestricted use, distribution, and reproduction in any medium, provided the original work is properly cited.

TODIM is a well-known multiple-criteria decision-making (MCDM) which considers the bounded rationality of decision makers (DMs) based on prospect theory (PT). However, in the classical TODIM, the perceived probability weighting function and the difference of the risk attitudes for gains and losses are not consistent with the original idea of PT. Moreover, probabilistic hesitant fuzzy information shows its superiority in handling the situation that the DMs hesitate among several possible values with different possibilities. Hence, a novel TODIM with probabilistic hesitant fuzzy information is proposed in this paper to simulate the perceptions of the DMs in PT. To show the advantages of the proposed method, a novel TODIM is combined with hesitant fuzzy information. Finally, a case study is carried out to demonstrate the feasibility of the proposed method, and a series of comparative analyses and the sensitivity analyses are used to show the stability of the proposed method.

\section{Introduction}

Decision makers (DMs) are considered to be completely rational among the existing multiple-criteria decision-making (MCDM) methods based on expected utility theory. However, the DMs are naturally bounded rational in real world. They are not able to obtain every detail of decision-making alternatives and are limited by their cognitions. Therefore, TODIM (TOmada deDecisão Iterativa Multicritério), a well-known MCDM method considering the bounded rational behaviors based on prospect theory (PT) [1], was proposed by Gomes and Lima [2]. It handles the vagueness and bounded rationality of the DMs to make the optimal choices based on multiple criteria.

However, the classical TODIM is based on crisp number which makes it restricted to express the vague perceptions of the DMs. Thus, the fuzzy sets (FSs) were introduced, and the TODIM had been extended to various FSs to provide more accurate and detailed information. The existing extensions of the TODIM are summarized in Table 1.

The TODIM has been not only extended to various fuzzy circumstances but also applied to various ranges of applications. After analyzing the existing TODIM, the application fields are summarized from the following aspects: supplier selection $[8,10,12,15,17,18,27,29]$, manufacture $[3,7,13,19,30,31]$, investment problem $[5,16,25,26,32]$, service evaluation $[23,24]$, personnel selection $[6,33]$, emergency plan selection $[9,14]$, site selection $[20,22]$, air quality [4], and power sources [21]. Undoubtedly, the TODIM has demonstrated its unparalleled advantages in solving the MCDM problems by considering the psychological factors of the DMs. However, according to our review, we find that most of the existing TODIMs ignore the importance of the transformed probability weight in the original PT. What is more, the risk attitudes shown in the classical TODIM are not inconsistent with PT which only works on the gains and losses. That is, the classical TODIM should be adjusted according to the original PT which permits a more scientific result in its application. Meanwhile, the DMs may be hesitant between several possible evaluation information under the highly uncertain circumstance. Hence, a hesitant fuzzy set (HFS) [34] is an effective tool to express the hesitant situation in decision- 
TABLE 1: Extensions of TODIM with various FSs.

\begin{tabular}{lc}
\hline FSs & References \\
\hline Interval number & {$[3,4]$} \\
Intuitionistic fuzzy set & {$[5]$} \\
Pythagorean fuzzy set & {$[6,7]$} \\
Q-rung orthopair fuzzy set & {$[8]$} \\
Trapezoidal fuzzy set & {$[4,9]$} \\
Trapezoidal intuitionistic fuzzy set & {$[10]$} \\
Probabilistic interval-valued hesitant fuzzy set & {$[11]$} \\
Multiset hesitant fuzzy set & {$[12]$} \\
Probabilistic dual hesitant fuzzy set & {$[13]$} \\
Intervalued Pythagorean fuzzy linguistic term set & {$[14]$} \\
Unbalanced hesitant fuzzy linguistic term set & {$[15]$} \\
Neutrosophic number & {$[16]$} \\
Interval type-2 fuzzy set & {$[17,18]$} \\
Interval-valued intuitionistic fuzzy set & {$[19,20]$} \\
Triangular fuzzy set & {$[3,9]$} \\
Triangular intuitionistic fuzzy set & {$[21,22]$} \\
Hesitant fuzzy set & {$[23]$} \\
Hesitant trapezoidal fuzzy set & {$[24]$} \\
Probabilistic hesitant fuzzy set & {$[25]$} \\
Intuitionistic linguistic term set & {$[26]$} \\
Hesitant fuzzy linguistic term set & {$[27,28]$} \\
Multiset hesitant fuzzy linguistic term set & {$[29]$} \\
Single-valued neutrosophic set & {$[30]$} \\
\hline
\end{tabular}

making processes. Besides, probabilistic hesitant fuzzy information is further proposed to depict the different probabilities of each hesitant fuzzy value in HFS [35]. Hence, this paper proposes the novel TODIM with probabilistic hesitant fuzzy information and hesitant fuzzy information, respectively, to fully illustrate the core idea of PT. Furthermore, according to the comparative analysis, we show the advantages of the novel TODIM with probabilistic hesitant fuzzy information.

The contributions of this paper are as follows: (i) a novel TODIM with probabilistic hesitant fuzzy information is proposed, which is fully aligned with the original idea of PT compared with the classical TODIM. (ii) The novel TODIM with hesitant fuzzy information also has been developed to show the advantages of probabilistic hesitant fuzzy information. (iii) In the novel TODIM, the different risk attitudes are considered and they only work on gains and losses instead of the consistent risk attitudes in the dominance function of the classical TODIM. Moreover, the transformed probability weight function is also included in the novel TODIM.

The outline of this paper is as follows: in Section 2, the basic concepts of PT, TODIM, and probabilistic hesitant fuzzy information are presented in detail. In Section 3, the existing researches about the TODIM are analyzed. And the novel TODIM is combined with probabilistic hesitant fuzzy information and hesitant fuzzy information according to the original PT from the perspective of dominance function. In Section 4, a case study about bus electric supplier selection problem is provided. Section 5 shows the superiority of the proposed methods by a series of comparative analyses, especially by comparing the novel TODIM under probabilistic hesitant fuzzy environment with the extension of TOPSIS. After that, the conclusions are presented in Section 6.
TABLE 2: Transformed probability weights.

\begin{tabular}{lcccc}
\hline \multirow{2}{*}{ Weights } & $c_{1}$ & $c_{2}$ & $c_{3}$ & $c_{4}$ \\
\hline$\pi_{12 j}\left(\omega_{j}^{\prime}\right)$ & 0.389 & 0.183 & 0.275 & 0.306 \\
$\pi_{13 j}\left(\omega_{j}^{\prime}\right)$ & 0.389 & 0.183 & 0.275 & 0.306 \\
$\pi_{14 j}\left(\omega_{j}^{\prime}\right)$ & 0.389 & 0.183 & 0.275 & 0.306 \\
$\pi_{21 j}\left(\omega_{j}^{\prime}\right)$ & 0.368 & 0.197 & 0.275 & 0.301 \\
$\pi_{23 j}\left(\omega_{j}^{\prime}\right)$ & 0.368 & 0.197 & 0.275 & 0.301 \\
$\pi_{24 j}\left(\omega_{j}^{\prime}\right)$ & 0.368 & 0.197 & 0.275 & 0.301 \\
$\pi_{31 j}\left(\omega_{j}^{\prime}\right)$ & 0.368 & 0.197 & 0.275 & 0.301 \\
$\pi_{32 j}\left(\omega_{j}^{\prime}\right)$ & 0.389 & 0.183 & 0.275 & 0.306 \\
$\pi_{34 j}\left(\omega_{j}^{\prime}\right)$ & 0.389 & 0.197 & 0.275 & 0.301 \\
$\pi_{41 j}\left(\omega_{j}^{\prime}\right)$ & 0.368 & 0.197 & 0.275 & 0.301 \\
$\pi_{42 j}\left(\omega_{j}^{\prime}\right)$ & 0.389 & 0.183 & 0.275 & 0.306 \\
$\pi_{43 j}\left(\omega_{j}^{\prime}\right)$ & 0.368 & 0.183 & 0.275 & 0.306 \\
\hline
\end{tabular}

TABLE 3: Relative weights.

\begin{tabular}{lcccc}
\hline \multirow{2}{*}{ Relative weights } & \multicolumn{4}{c}{ Criteria } \\
& $c_{1}$ & $c_{2}$ & $c_{3}$ & $c_{4}$ \\
\hline$\pi_{12 j^{*}}$ & 1 & 0.47 & 0.707 & 0.789 \\
$\pi_{13 j^{*}}$ & 1 & 0.47 & 0.707 & 0.789 \\
$\pi_{14 j^{*}}$ & 1 & 0.47 & 0.707 & 0.789 \\
$\pi_{21 j^{*}}$ & 1 & 0.537 & 0.749 & 0.82 \\
$\pi_{23 j^{*}}$ & 1 & 0.537 & 0.749 & 0.82 \\
$\pi_{24 j^{*}}$ & 1 & 0.537 & 0.749 & 0.82 \\
$\pi_{31 j^{*}}$ & 1 & 0.537 & 0.749 & 0.82 \\
$\pi_{32 j^{*}}$ & 1 & 0.47 & 0.707 & 0.789 \\
$\pi_{34 j^{*}}$ & 1 & 0.508 & 0.708 & 0.775 \\
$\pi_{41 j^{*}}$ & 1 & 0.537 & 0.749 & 0.82 \\
$\pi_{42 j^{*}}$ & 1 & 0.47 & 0.707 & 0.789 \\
$\pi_{43 j^{*}}$ & 1 & 0.497 & 0.747 & 0.834 \\
\hline
\end{tabular}

TABLE 4: Relative prospect dominance degrees under each criterion.

\begin{tabular}{lcccc}
\hline \multirow{2}{*}{ Relative dominance degrees } & \multicolumn{4}{c}{ Criterion } \\
& $c_{1}$ & $c_{2}$ & $c_{3}$ & $c_{4}$ \\
\hline$\varphi_{j^{*}}\left(A_{1}, A_{2}\right)$ & -37.23 & -139.33 & -36.21 & -33.35 \\
$\varphi_{j^{*}}\left(A_{1}, A_{3}\right)$ & -9.25 & -55.75 & -32.14 & -50.83 \\
$\varphi_{j^{*}}\left(A_{1}, A_{4}\right)$ & -36.46 & -63.05 & -25.14 & -41.38 \\
$\varphi_{j^{*}}\left(A_{2}, A_{1}\right)$ & 1.80 & 1.70 & 0.92 & 1.04 \\
$\varphi_{j^{*}}\left(A_{2}, A_{3}\right)$ & 2.12 & 1.16 & 1.49 & 2.23 \\
$\varphi_{j^{*}}\left(A_{2}, A_{4}\right)$ & 2.58 & 1.07 & 0.98 & 1.78 \\
$\varphi_{j^{*}}\left(A_{3}, A_{1}\right)$ & 0.45 & 0.68 & 0.82 & 1.59 \\
$\varphi_{j^{*}}\left(A_{3}, A_{2}\right)$ & -43.89 & -94.96 & -58.35 & -71.57 \\
$\varphi_{j^{*}}\left(A_{3}, A_{4}\right)$ & -40.28 & 0.40 & 0.62 & 0.84 \\
$\varphi_{j^{*}}\left(A_{4}, A_{1}\right)$ & 1.76 & 0.77 & 0.64 & 1.29 \\
$\varphi_{j^{*}}\left(A_{4}, A_{2}\right)$ & -53.35 & -88.08 & -38.39 & -57.11 \\
$\varphi_{j^{*}}\left(A_{4}, A_{3}\right)$ & 1.95 & -32.87 & -24.37 & -26.89 \\
\hline
\end{tabular}

\section{Some Concepts}

In this section, some fundamental concepts are presented, including PT, TODIM, and the probabilistic hesitant fuzzy information. They are the essential parts of this paper. 
TABle 5: Prospect dominance degrees.

\begin{tabular}{lccc}
\hline$\psi\left(A_{1}, A_{2}\right)-246.12$ & $\psi\left(A_{2}, A_{1}\right) 5.46$ & $\psi\left(A_{3}, A_{1}\right) 3.53$ & $\psi\left(A_{4}, A_{1}\right) 4.46$ \\
$\psi\left(A_{1}, A_{3}\right)-147.97$ & $\psi\left(A_{2}, A_{3}\right) 7.00$ & $\psi\left(A_{3}, A_{2}\right)-268.77$ & $\psi\left(A_{4}, A_{2}\right)-236.93$ \\
$\psi\left(A_{1}, A_{4}\right)-166.03$ & $\psi\left(A_{2}, A_{4}\right) 6.41$ & $\psi\left(A_{3}, A_{4}\right)-38.42$ & $\psi\left(A_{4}, A_{3}\right)-82.19$ \\
\hline
\end{tabular}

TABLE 6: Overall prospect dominance degrees.

\begin{tabular}{lccc}
\hline$\Omega\left(A_{1}\right)$ & $\Omega\left(A_{2}\right)$ & $\Omega\left(A_{3}\right)$ & $\Omega\left(A_{4}\right)$ \\
\hline 0 & 1 & 0.44 & 0.42 \\
\hline
\end{tabular}

TABLE 7: Relative weights.

\begin{tabular}{llll}
\hline$\omega_{1 r}$ & $\omega_{2 r}$ & $\omega_{3 r}$ & $\omega_{4 r}$ \\
\hline 1 & 0.28 & 0.57 & 0.68 \\
\hline
\end{tabular}

TABle 8: Relative prospect dominance degrees.

\begin{tabular}{lcccc}
\hline \multirow{2}{*}{ Relative dominance degrees } & \multicolumn{4}{c}{ Criteria } \\
& $c_{1}$ & $c_{2}$ & $c_{3}$ & $c_{4}$ \\
\hline$\varphi_{j}\left(A_{1}, A_{2}\right)$ & -1.88 & -4.85 & -2.02 & -1.87 \\
$\varphi_{j}\left(A_{1}, A_{3}\right)$ & -0.85 & -2.88 & -1.89 & -2.38 \\
$\varphi_{j}\left(A_{1}, A_{4}\right)$ & -1.86 & -3.09 & -1.64 & -2.11 \\
$\varphi_{j}\left(A_{2}, A_{1}\right)$ & 1.67 & 1.23 & 1.01 & 1.13 \\
$\varphi_{j}\left(A_{2}, A_{3}\right)$ & 1.83 & 0.99 & 1.33 & 1.74 \\
$\varphi_{j}\left(A_{2}, A_{4}\right)$ & 2.05 & 0.95 & 1.05 & 1.53 \\
$\varphi_{j}\left(A_{3}, A_{1}\right)$ & 0.76 & 0.73 & 0.95 & 1.44 \\
$\varphi_{j}\left(A_{3}, A_{2}\right)$ & -2.06 & -3.90 & -2.65 & -2.88 \\
$\varphi_{j}\left(A_{3}, A_{4}\right)$ & -1.95 & 0.55 & 0.82 & 1.01 \\
$\varphi_{j}\left(A_{4}, A_{1}\right)$ & 1.65 & 0.78 & 0.82 & 1.28 \\
$\varphi_{j}\left(A_{4}, A_{2}\right)$ & -2.30 & -3.74 & -2.09 & -2.54 \\
$\varphi_{j}\left(A_{4}, A_{3}\right)$ & 1.74 & -2.16 & -1.63 & -1.67 \\
\hline
\end{tabular}

2.1. Prospect Theory. PT is a major innovation in describing the bounded behavior of the DMs. It makes choices by the prospect value $V\left(x_{i}\right)$, which is calculated by multiplying the values of the value function $v\left(x_{i j}\right)$ and the weight function $w\left(p_{j}\right)$. Let $A=\left\{A_{1}, A_{2}, \ldots, A_{n}\right\}$ be a finite set of alternatives, $C=\left\{c_{1}, c_{2}, \ldots, c_{m}\right\}$ be a finite set of criteria, and $N=\{1,2, \ldots, n\}, M=\{1,2, \ldots, m\}, i \in N$, $j \in M$. The prospect value is obtained by the following equations:

$$
\begin{aligned}
& V\left(x_{i}\right)=\sum_{j=1}^{m} v\left(x_{i j}\right) w\left(p_{j}\right), \\
& v\left(x_{i j}\right)= \begin{cases}-\lambda\left(x_{0}-x_{i j}\right)^{\beta} & x_{i j}-x_{0}<0, \\
\left(x_{i j}-x_{0}\right)^{\alpha} & x_{i j}-x_{0} \geq 0,\end{cases}
\end{aligned}
$$

$$
w\left(p_{j}\right)= \begin{cases}\frac{p_{j}^{\delta}}{\left[p_{j}^{\delta}+\left(1-p_{j}\right)^{\delta}\right]^{1 / \delta}}, & x_{i j}-x_{0}<0, \\ \frac{p_{j}^{\gamma}}{\left[p_{j}^{\gamma}+\left(1-p_{j}\right)^{\gamma}\right]^{1 / \gamma}}, & x_{i j}-x_{0} \geq 0,\end{cases}
$$

where $x_{i j}$ denotes the evaluation value of the alternative $A_{i}$ over $c_{j} ; x_{0}$ represents the reference point; $p_{j}$ is the weight of $c_{j}$; and $\alpha, \beta, \lambda, \delta$, and $\gamma$ are the corresponding parameters acquired from the experiments. According to the experiment in the classical PT [31], $\alpha=\beta=0.88, \lambda=2.25$, $\delta=0.69$, and $\gamma=0.61$.

2.2. TODIM. The TODIM [2] is an effective MCDM method to simulate the behaviors of the DMs. It considers the risk attitudes of DMs during the decision-making processes and measures the alternative by comparing the relative dominance with other alternatives. The procedure of the classical TODIM is shown as follows:

Step 1: obtain the original decision-making information including the evaluation information $X=\left(x_{i j}\right)_{n \times m}$ of the alternative $A_{i}$ regarding the criterion $c_{j}$ and the weighting vector of the criterion $\omega$ :

$$
\begin{aligned}
X & =\left(\begin{array}{ccc}
x_{11} & \cdots & x_{1 m} \\
\vdots & \ddots & \vdots \\
x_{n 1} & \cdots & x_{n m}
\end{array}\right)=\left(x_{i j}\right)_{n \times m}, \\
\omega & =\left(\omega_{1}, \omega_{2}, \ldots, \omega_{m}\right), \\
\sum_{j=1}^{m} \omega_{j} & =1 .
\end{aligned}
$$

Step 2: normalize the decision matrix $X=\left[x_{i j}\right]_{n \times m}$ into $X=\left(\breve{x}_{i j}\right)_{n \times m}$ according to the cost criterion and benefit criterion:

$$
\breve{x}_{i j}= \begin{cases}x_{i j}, & c_{j} \text { is the benefit criterion, } \\ -x_{i j}, & c_{j} \text { is the cost criterion. }\end{cases}
$$

Step 3: obtain the relative weights $\omega_{j r}(j=1,2, \ldots, m)$ of the criterion $c_{j}(j=1,2, \ldots, m)$ :

$$
\omega_{j r}=\frac{\omega_{j}}{\omega_{r}}
$$

where $r, j \in M, \omega_{r}=\max \left(\omega_{j} \mid j \in M\right)$ and $c_{r}$ is called the reference criterion. 
TABle 9: Prospect dominance degrees.

\begin{tabular}{lccc}
\hline$\psi_{j}\left(A_{1}, A_{2}\right)-5.76$ & $\psi_{j}\left(A_{2}, A_{1}\right) 3.82$ & $\psi_{j}\left(A_{3}, A_{1}\right) 3.14$ & $\psi_{j}\left(A_{4}, A_{1}\right) 3.75$ \\
$\psi_{j}\left(A_{1}, A_{3}\right)-5.11$ & $\psi_{j}\left(A_{2}, A_{3}\right) 4.91$ & $\psi_{j}\left(A_{3}, A_{2}\right)-7.59$ & $\psi_{j}\left(A_{4}, A_{2}\right)-6.93$ \\
$\psi_{j}\left(A_{1}, A_{4}\right)-5.61$ & $\psi_{j}\left(A_{2}, A_{4}\right) 4.63$ & $\psi_{j}\left(A_{3}, A_{4}\right)-0.12$ & $\psi_{j}\left(A_{4}, A_{3}\right)-1.56$ \\
\hline
\end{tabular}

TABle 10: Overall dominance degrees.

\begin{tabular}{lccc}
\hline$\Omega\left(A_{1}\right)$ & $\Omega\left(A_{2}\right)$ & $\Omega\left(A_{3}\right)$ & $\Omega\left(A_{4}\right)$ \\
\hline 0 & 1 & 0.40 & 0.39 \\
\hline
\end{tabular}

TABle 11: Transformed probability weights.

\begin{tabular}{lcccc}
\hline \multirow{2}{*}{ Weights } & \multicolumn{4}{c}{ Criteria } \\
& $c_{1}$ & $c_{2}$ & $c_{3}$ & $c_{4}$ \\
\hline$\pi_{12 j}\left(\omega_{j}^{\prime}\right)$ & 0.394 & 0.179 & 0.275 & 0.302 \\
$\pi_{13 j}\left(\omega_{j}^{\prime}\right)$ & 0.394 & 0.179 & 0.275 & 0.302 \\
$\pi_{14 j}\left(\omega_{j}^{\prime}\right)$ & 0.394 & 0.179 & 0.275 & 0.302 \\
$\pi_{21 j}\left(\omega_{j}^{\prime}\right)$ & 0.372 & 0.195 & 0.276 & 0.298 \\
$\pi_{23 j}\left(\omega_{j}^{\prime}\right)$ & 0.372 & 0.195 & 0.275 & 0.298 \\
$\pi_{24 j}\left(\omega_{j}^{\prime}\right)$ & 0.372 & 0.195 & 0.276 & 0.298 \\
$\pi_{31 j}\left(\omega_{j}^{\prime}\right)$ & 0.372 & 0.195 & 0.276 & 0.298 \\
$\pi_{32 j}\left(\omega_{j}^{\prime}\right)$ & 0.394 & 0.179 & 0.276 & 0.302 \\
$\pi_{34 j}\left(\omega_{j}^{\prime}\right)$ & 0.394 & 0.195 & 0.276 & 0.298 \\
$\pi_{41 j}\left(\omega_{j}^{\prime}\right)$ & 0.372 & 0.195 & 0.276 & 0.298 \\
$\pi_{42 j}\left(\omega_{j}^{\prime}\right)$ & 0.394 & 0.179 & 0.275 & 0.302 \\
$\pi_{43 j}\left(\omega_{j}^{\prime}\right)$ & 0.372 & 0.179 & 0.275 & 0.302 \\
\hline
\end{tabular}

TABLE 12: Relative prospect dominance degrees.

\begin{tabular}{lcccc}
\hline \multirow{2}{*}{ Relative dominance degrees } & \multicolumn{4}{c}{ Criteria } \\
& $c_{1}$ & $c_{2}$ & $c_{3}$ & $c_{4}$ \\
\hline$\psi_{j}\left(A_{1}, A_{2}\right)$ & -37.91 & -106.24 & -52.20 & -68.83 \\
$\psi_{j}\left(A_{1}, A_{3}\right)$ & -27.06 & -69.83 & -50.00 & -39.45 \\
$\psi_{j}\left(A_{1}, A_{4}\right)$ & -31.77 & -37.94 & -38.82 & -18.07 \\
$\psi_{j}\left(A_{2}, A_{1}\right)$ & 1.89 & 1.26 & 1.34 & 2.10 \\
$\psi_{j}\left(A_{2}, A_{3}\right)$ & 0.86 & 0.54 & -38.44 & 1.08 \\
$\psi_{j}\left(A_{2}, A_{4}\right)$ & 1.27 & 0.91 & 1.05 & 1.69 \\
$\psi_{j}\left(A_{3}, A_{1}\right)$ & 1.35 & 0.83 & 1.28 & 1.20 \\
$\psi_{j}\left(A_{3}, A_{2}\right)$ & -17.27 & -45.29 & 0.99 & -35.35 \\
$\psi_{j}\left(A_{3}, A_{4}\right)$ & -13.98 & 0.44 & 0.37 & 0.74 \\
$\psi_{j}\left(A_{4}, A_{1}\right)$ & 1.58 & 0.45 & 1.00 & 0.55 \\
$\psi_{j}\left(A_{4}, A_{2}\right)$ & -25.47 & -76.61 & -41.09 & -55.39 \\
$\psi_{j}\left(A_{4}, A_{3}\right)$ & 0.70 & -37.21 & -14.48 & -24.25 \\
\hline
\end{tabular}

TABLE 13: Overall prospect dominance degrees.

\begin{tabular}{lccc}
\hline$\Omega\left(A_{1}\right)$ & $\Omega\left(A_{2}\right)$ & $\Omega\left(A_{3}\right)$ & $\Omega\left(A_{4}\right)$ \\
\hline 0 & 1 & 0.86 & 0.56 \\
\hline
\end{tabular}

TABLE 14: Relative weights.

\begin{tabular}{lccc}
\hline$\omega_{1 r}$ & $\omega_{2 r}$ & $\omega_{3 r}$ & $\omega_{4 r}$ \\
\hline 1 & 0.27 & 0.55 & 0.65
\end{tabular}

TABLE 15: Relative prospect dominance degrees.

\begin{tabular}{lcccc}
\hline \multirow{2}{*}{ Relative dominance degrees } & \multicolumn{4}{c}{ Criteria } \\
& $c_{1}$ & $c_{2}$ & $c_{3}$ & $c_{4}$ \\
\hline$\varphi_{j}\left(A_{1}, A_{2}\right)$ & -1.89 & -4.18 & -2.48 & -2.83 \\
$\varphi_{j}\left(A_{1}, A_{3}\right)$ & -1.56 & -3.29 & -2.42 & -2.07 \\
$\varphi_{j}\left(A_{1}, A_{4}\right)$ & -1.71 & -2.33 & -2.10 & -1.33 \\
$\varphi_{j}\left(A_{2}, A_{1}\right)$ & 1.72 & 1.03 & 1.25 & 1.67 \\
$\varphi_{j}\left(A_{2}, A_{3}\right)$ & 1.10 & 0.63 & -2.10 & 1.15 \\
$\varphi_{j}\left(A_{2}, A_{4}\right)$ & 1.37 & 0.85 & 1.09 & 1.48 \\
$\varphi_{j}\left(A_{3}, A_{1}\right)$ & 1.42 & 0.81 & 1.22 & 1.22 \\
$\varphi_{j}\left(A_{3}, A_{2}\right)$ & -1.21 & -2.57 & 1.06 & -1.94 \\
$\varphi_{j}\left(A_{3}, A_{4}\right)$ & -1.07 & 0.57 & 0.61 & 0.94 \\
$\varphi_{j}\left(A_{4}, A_{1}\right)$ & 1.56 & 0.57 & 1.06 & 0.78 \\
$\varphi_{j}\left(A_{4}, A_{2}\right)$ & -1.51 & -3.47 & -2.17 & -2.51 \\
$\varphi_{j}\left(A_{4}, A_{3}\right)$ & 0.97 & -2.33 & -1.21 & -1.58 \\
\hline
\end{tabular}

Step 4: acquire the prospect dominance degree $\psi\left(A_{i}, A_{k}\right)$ of each alternative $A_{i}$ over the rest of the alternatives $A_{k}(k=1,2, \ldots, n, k \neq i)$ :

$$
\psi\left(A_{i}, A_{k}\right)=\sum_{j=1}^{m} \varphi_{j}\left(A_{i}, A_{k}\right), \quad i, k \in N
$$

where the relative dominance degree $\varphi_{j}\left(A_{i}, A_{k}\right)$ over $c_{j}$ is calculated by the following equation, and the parameter $\lambda$ denotes the attenuation factor of the losses:

$$
\varphi_{j}\left(A_{i}, A_{k}\right)= \begin{cases}\sqrt{\frac{\omega_{j r}}{\sum_{j=1}^{m} \omega_{j r}}\left(\breve{x}_{i j}-\breve{x}_{k j}\right)}, & \breve{x}_{i j}-\breve{x}_{k j}>0, \\ 0, & \breve{x}_{i j}-\breve{x}_{k j}=0, \\ \frac{-1}{\lambda} \sqrt{\frac{\sum_{j=1}^{m} \omega_{j r}}{\omega_{j r}}\left(\breve{x}_{k j}-\breve{x}_{i j}\right),} & \breve{x}_{i j}-\breve{x}_{k j}<0 .\end{cases}
$$


TABle 16: The dominance degrees.

\begin{tabular}{lccc}
\hline$\psi_{j}\left(A_{1}, A_{2}\right)-11.39$ & $\psi_{j}\left(A_{2}, A_{1}\right) 5.67$ & $\psi_{j}\left(A_{3}, A_{1}\right) 4.67$ & $\psi_{j}\left(A_{4}, A_{1}\right) 3.97$ \\
$\psi_{j}\left(A_{1}, A_{3}\right)-9.35$ & $\psi_{j}\left(A_{2}, A_{3}\right) 0.78$ & $\psi_{j}\left(A_{3}, A_{2}\right)-4.67$ & $\psi_{j}\left(A_{4}, A_{2}\right)-9.65$ \\
$\psi_{j}\left(A_{1}, A_{4}\right)-7.47$ & $\psi_{j}\left(A_{2}, A_{4}\right) 4.80$ & $\psi_{j}\left(A_{3}, A_{4}\right) 1.05$ & $\psi_{j}\left(A_{4}, A_{3}\right)-4.15$ \\
\hline
\end{tabular}

TABLE 17: Overall prospect dominance degrees.

\begin{tabular}{lccc}
\hline$\Omega\left(A_{1}\right)$ & $\Omega\left(A_{2}\right)$ & $\Omega\left(A_{3}\right)$ & $\Omega\left(A_{4}\right)$ \\
\hline 0 & 1 & 0.74 & 0.47 \\
\hline
\end{tabular}

TABLE 18: The results of 4 methods.

\begin{tabular}{lcccc}
\hline & \multicolumn{3}{c}{$\begin{array}{c}\text { Overall prospect dominance } \\
\text { degrees }\end{array}$} \\
& $\Omega\left(A_{1}\right)$ & $\Omega\left(A_{2}\right)$ & $\Omega\left(A_{3}\right)$ & $\Omega\left(A_{4}\right)$ \\
\hline $\begin{array}{l}\text { Novel TODIM with } \\
\text { probabilistic hesitant fuzzy }\end{array}$ & 0 & 1 & 0.44 & 0.42 \\
$\begin{array}{l}\text { information } \\
\text { Extended TODIM with } \\
\text { probabilistic hesitant fuzzy }\end{array}$ & 0 & 1 & 0.40 & 0.39 \\
$\begin{array}{l}\text { information } \\
\begin{array}{l}\text { Novel TODIM with hesitant } \\
\text { fuzzy information }\end{array}\end{array}$ & 0 & 1 & 0.86 & 0.56 \\
$\begin{array}{l}\text { Extended TODIM with hesitant } \\
\text { fuzzy information }\end{array}$ & 0 & 1 & 0.74 & 0.47 \\
\hline
\end{tabular}

Step 5: calculate the overall prospect dominance degree $\Omega\left(A_{i}\right)$ :

$$
\Omega\left(A_{i}\right)=\frac{\sum_{k=1}^{n} \psi\left(A_{i}, A_{k}\right)-\min _{i}\left\{\sum_{k=1}^{n} \psi\left(A_{i}, A_{k}\right)\right\}}{\max _{i}\left\{\sum_{k=1}^{n} \psi\left(A_{i}, A_{k}\right)\right\}-\min _{i}\left\{\sum_{k=1}^{n} \psi\left(A_{i}, A_{k}\right)\right\} .}
$$

Step 6: rank the alternatives according to the overall dominance degree of each alternative $\Omega\left(A_{i}\right)$. The bigger $\Omega\left(A_{i}\right)$ is, the better the alternative $A_{i}$ will be:

$$
A_{i}>A_{i^{\prime}} \Longleftrightarrow \Omega\left(A_{i}\right)>\Omega\left(A_{i^{\prime}}\right)
$$

2.3. Probabilistic Hesitant Fuzzy Information. Let $X$ be a fixed set, and a probabilistic hesitant fuzzy set (P-HFS) on $X$ is expressed by

$$
H=\left\{<x_{i}, h_{x_{i}}\left(p_{x_{i}}\right)>\mid x_{i} \in X\right\},
$$

where $h_{x_{i}}(\cdot)$ is called the probabilistic hesitant fuzzy element (P-HFE). It represents all the possible membership degrees of $x_{i} \in X$ in $[0,1] . p_{x}$ is a set of probabilities associated with $h_{x_{i}}(\cdot)$ and $\sum p_{x_{i}}=1$. To be more concise, we denote the P-HFE $h_{x_{i}}\left(p_{x_{i}}\right)$ as $h(p)=\left\{h^{t}\left(p^{t}\right) \mid t=1,2, \ldots, \# h(p)\right\}$, where $\# h(p)$ is the number of all possible membership degrees, and $\sum_{t=1}^{\# h(p)} p^{t}=1$. If $\sum_{t=1}^{\# h(p)} p^{t}<1$ for a P-HFE $h(p)$, it can be transformed into $\dot{h}(p)$, which is defined as $\dot{h}(p)=\left\{h^{t}\left(\dot{p}^{t}\right) \mid t=1,2, \ldots, \# \dot{h}(p)\right\}$, where $\sum_{t=1}^{\# \dot{h}(p)} \dot{p}^{t}=1$ and $\dot{p}^{t}=p^{t} / \sum_{t=1}^{\# h(p)} p^{t},(t=1,2, \ldots, \# h(p))$ [35]. To compare two pieces of probabilistic hesitant fuzzy information, the score function $\rho(h(p))$ and the deviation function $\sigma(h(p))$ are defined as

$$
\begin{aligned}
\rho(h(p)) & =\frac{\sum_{t=1}^{\# h(p)} p^{t} \times h^{t}\left(p^{t}\right)}{\sum_{t=1}^{\# h(p)} p^{t}}, \\
\sigma(h(p)) & =\frac{\sum_{t=1}^{\# h(p)}\left(p^{t} \times\left(h^{t}\left(p^{t}\right)-\rho(h(p))\right)^{2}\right)}{\sum_{t=1}^{\# h(p)} p^{t}} .
\end{aligned}
$$

The comparison rules of two P-HFEs are expressed as

(1) If $\rho\left(h_{1}(p)\right)>\rho\left(h_{2}(p)\right)$, then $h_{1}(p)>h_{2}(p)$

(2) If $\rho\left(h_{1}(p)\right)<\rho\left(h_{2}(p)\right)$, then $h_{1}(p)<h_{2}(p)$

(3) If $\rho\left(h_{1}(p)\right)=\rho\left(h_{2}(p)\right)$, then

(1) If $\sigma\left(h_{1}(p)\right)>\sigma\left(h_{2}(p)\right)$, then $h_{1}(p)<h_{2}(p)$

(2) If $\sigma\left(h_{1}(p)\right)<\sigma\left(h_{2}(p)\right)$, then $h_{1}(p)>h_{2}(p)$

(3) If $\sigma\left(h_{1}(p)\right)=\sigma\left(h_{2}(p)\right)$, then $h_{1}(p)=h_{2}(p)$

Distance is also an important way to measure the relationship between two pieces of fuzzy information, and the same length of two P-HFEs is the premise for distance measurement. Therefore, probabilistic hesitant fuzzy values should be added to the shorter P-HFE. For example, let $h_{1}(p)$ and $h_{2}(p)$ be the two P-HFEs; if $\# h_{1}(p)<\# h_{2}(p)$, $\# h_{2}(p)-\# h_{1}(p)$ number of probabilistic hesitant fuzzy values should be added to $h_{1}(p)$. In this paper, the largest possible probabilistic hesitant fuzzy value is added to $h_{1}(p)$, and the corresponding probability is zero. In fact, there is no effect on the score function and the deviation function of the original P-HFE by adding a term with probability to be zero. Besides, the ordered P-HFE satisfies the following conditions:

(1) For an ascending ordered P-HFE, $p^{t} h^{t}\left(p^{t}\right) \leq p^{t+1} h^{t+1}\left(p^{t+1}\right)$

(2) For a descending ordered P-HFE, $p^{t} h^{t}\left(p^{t}\right) \geq p^{t+1} h^{t+1}\left(p^{t+1}\right)$

(3) If $p^{t} h^{t}\left(p^{t}\right)=p^{t+1} h^{t+1}\left(p^{t+1}\right)$ and the orders are determined by $p^{t}$ and $p^{t+1}$, then

(1) For an ascending ordered P-HFE, $p^{t}<p^{t+1}$

(2) For a descending ordered P-HFE, $p^{t}>p^{t+1}$

(3) If $p^{t}=p^{t+1}$, the sequence of those two P-HFEs is random for both ascending ordered P-HFE and descending ordered P-HFE 
Based on the ordered probabilistic hesitant fuzzy information, the Hamming distance is referred to [25] which is presented in the following equation:

$$
d\left(h_{1}, h_{2}\right)=\frac{1}{\# h_{1}(p)} \sum_{t=1}^{\# h_{1}(p)}\left|p_{1}^{t} h_{1}^{t}\left(p_{1}^{t}\right)-p_{2}^{t} h_{2}^{t}\left(p_{2}^{t}\right)\right| .
$$

For convenience, the below probabilistic hesitant fuzzy information satisfies: $\sum_{t=1}^{\# h^{\prime}\left(p^{\prime}\right)} p^{\prime t}=1$, and it is ordered and standardized.

\section{A Novel TODIM with Probabilistic Hesitant Fuzzy Information}

This section firstly goes through the existing researches of the TODIM based on various kinds of fuzzy information. From the perspective of dominance function, the necessity of improving TODIM is also presented. According to the detailed analysis, we figure out that the probabilistic hesitant fuzzy information has great superiority in expressing the different hesitation degrees of the DMs, and the novel TODIM is more reasonable which derives from the original PT considering the importance of the transformed probability weight function during the decision-making process. Subsequently, a novel TODIM with probabilistic hesitant fuzzy information is proposed in this section. For the sake of comparison, the novel TODIM with hesitant fuzzy information is also given in the following part.

\subsection{Analysis of the Existing Researches about the TODIM with} Fuzzy Information. The TODIM is known as an effective way to deal with the MCDM problems derived from PT, and it has advantages in expressing the behaviors of the DMs by using gains and losses. Actually, the crisp number is usually hard to access in the real world. Under this circumstance, the TODIM is applied to various FSs as analyzed in Table 1.

According to the review of extensions of the TODIM with fuzzy information, we find that most extensions are based on the classical TODIM, as shown in Section 2.2. That is, the risk attitudes work on the product of relative weight and the perceived gains or losses through the square root in the dominance function (equation (8)) which is inconsistent with the original PT (equation (2)). Besides, the existing TODIM calculates the relative weight by using objective probability instead of using the transformed probability weight function shown in equation (3). Actually, the dominance function is the main part to express the idea of PT. Hence, this section will show the model of the dominance function with fuzzy information.
Krohling and Souza [9] developed a TODIM by adjusting dominance function with trapezoidal fuzzy number as shown in the following equation:

$$
\varphi_{j}\left(A_{i}, A_{k}\right)= \begin{cases}\sqrt{\frac{\omega_{j k}}{\sum_{j=1}^{m} \omega_{j k}} d\left(r_{i j}, r_{k j}\right),} & r_{i j}>r_{k j}, \\ 0, & r_{i j}=r_{k j}, \\ \frac{-1}{\theta} \sqrt{\frac{\sum_{j=1}^{m} \omega_{j k}}{\omega_{j k}}} d\left(r_{k j}, r_{i j}\right), & r_{i j}<r_{k j},\end{cases}
$$

where $\omega_{j k}$ is the relative weight calculated from the original weight; $\theta$ is the attenuation factor of the losses; $r_{i j}$ and $r_{k j}$ are two FSs; and $d(\cdot)$ is the distance between $r_{i j}$ and $r_{k j}$.

According to equation (15), the dominance function excludes the distance outside the square root. However, some researchers hold the view that the above dominance function (equation (15)) is far more deviating from the original PT. Hence, there is another progress proposed by Peng et al. [12] through adjusting the square number $k$ as shown in equation (16). The distance of fuzzy evaluation information is included in the square root, which is similar to the classical TODIM:

$$
\varphi_{j}\left(A_{i}, A_{k}\right)= \begin{cases}\sqrt[k]{\frac{\omega_{j r}}{\sum_{j=1}^{m} \omega_{j r}} d\left(r_{i j}, r_{k j}\right)}, & r_{i j}>r_{k j}, \\ 0, & r_{i j}=r_{k j}, \\ \frac{-1}{\lambda} \sqrt[k]{\frac{\sum_{j=1}^{m} \omega_{j r}}{\omega_{k}} d\left(r_{i j}, r_{k j}\right),} & r_{i j}<r_{k j},\end{cases}
$$

where $k$ is the regulating variable that is determined by the preference of the DMs, and when $k=2$, the dominance function perfectly agrees with the classical TODIM.

Tan et al. [36] thought that the square root or $k$ used in the former dominance functions does not reflect the core idea of PT. The parameters could be different, which is shown in the experiments, while the square root or $k$ is the same value all the time. Based on this, the dominance function was modified as follows where risk attitudes work on the product of the relative weight and distances: 


$$
\varphi_{j}\left(A_{i}, A_{k}\right)= \begin{cases}\left(\frac{\omega_{j r}}{\sum_{j=1}^{m} \omega_{j r}} d\left(r_{i j}, r_{k j}\right)\right)^{\alpha}, & r_{i j}>r_{k j}, \\ 0, & r_{i j}=r_{k j}, \\ \frac{-1}{\theta}\left(\frac{\sum_{j=1}^{m} \omega_{j r}}{\omega_{k}} d\left(r_{i j}, r_{k j}\right)\right)^{\beta}, & r_{i j}<r_{k j} .\end{cases}
$$

Li et al. [28] insisted that in original PT, weight should be the form of weight function rather than the original weight. Hence, the original weight was replaced with the weight function based on (17) in their work. However, Tian et al. [32] thought that the risk attitudes only work on the gains or losses according to the value function based on PT and do not work on the weight. Then, the dominance function was adjusted as

$$
\varphi_{j}\left(A_{i}, A_{k}\right)= \begin{cases}\frac{w_{i j k}\left(x_{i j}-x_{k j}\right)^{\alpha}}{\sum_{j^{*}=1}^{m} w_{i j k}}, & x_{i j}>x_{k j}, \\ 0, & x_{i j}=x_{k j}, \\ \frac{-\lambda\left(\sum_{j=1}^{m} w_{i j k}\right)\left(x_{k j}-x_{k j}\right)^{\beta}}{w_{i j k}}, & x_{i j}<x_{k j},\end{cases}
$$

where $\alpha, \beta$, and $\lambda$ are the parameters obtained by experiments. In their work, the transformed probability weight is considered in the decision-making process instead of the original weight. The different preferences of the DMs on gains and losses are well described in this way. More importantly, the core idea of PT is fully illustrated by the risk attitudes which work on the gains or the losses. However, this TODIM has not been extended to various FSs. Therefore, in this paper, we are dedicated to adopting the framework of this novel TODIM, which comprehensively explains the idea of PT, and combining it with probabilistic hesitant fuzzy information.
3.2. Procedure of the Novel TODIM with Probabilistic Hesitant Fuzzy Information. Based on the above analysis, this section presents a new procedure of the novel TODIM with probabilistic hesitant fuzzy information, which is based on the idea of the original PT. The procedure is given as follows:

Step 1: obtain the original evaluation information matrix $Y=\left(h_{i j}\left(p_{i j}\right)\right)_{n \times m}$ according to equation (4) and the weight of the corresponding criterion. Both the evaluation information and the weight satisfy the characteristic of the P-HFE:

$$
Y=\left(\begin{array}{ccc}
h_{11}\left(p_{11}\right) & \cdots & h_{1 m}\left(p_{1 m}\right) \\
\vdots & \ddots & \vdots \\
h_{n 1}\left(p_{n 1}\right) & \cdots & h_{n m}\left(p_{n m}\right)
\end{array}\right)=\left(h_{i j}\left(p_{i j}\right)\right)_{n \times m},
$$

$$
\omega=\left(h_{\omega_{1}}\left(p_{\omega_{1}}\right), h_{\omega_{2}}\left(p_{\omega_{2}}\right), \ldots, h_{\omega_{m}}\left(p_{\omega_{m}}\right)\right),
$$

where $i \in N, j \in M ; h_{i j}\left(p_{i j}\right)$ is the evaluation information of the alternative $A_{i}$ over the criterion $c_{j}$; and $h_{\omega_{j}}\left(p_{\omega_{j}}\right)$ is the weighting information of $c_{j}$.

Step 2: normalize the evaluation information matrix according to Section 2.3:

$$
\begin{aligned}
Y^{\prime} & =\left(\begin{array}{ccc}
h_{11}^{\prime}\left(p_{11}^{\prime}\right) & \cdots & h_{1 m}^{\prime}\left(p_{1 m}^{\prime}\right) \\
\vdots & \ddots & \vdots \\
h_{n 1}^{\prime}\left(p_{n 1}^{\prime}\right) & \cdots & h_{n m}^{\prime}\left(p_{n m}^{\prime}\right)
\end{array}\right) \\
& =\left(h_{i j}^{\prime}\left(p_{i j}^{\prime}\right)\right)_{n \times m}, \\
\omega^{\prime} & =\left(\omega_{1}^{\prime}, \omega_{2}^{\prime}, \ldots, \omega_{m}^{\prime}\right),
\end{aligned}
$$

where $\quad \sum_{j=1}^{m} p_{i j}^{\prime}=1 \quad(i \in N), \quad \sum_{j=1}^{m} \omega_{j}^{\prime}=1 ; \quad \omega_{j}^{\prime}=\omega_{j} /$ $\sum_{j=1}^{m} \omega_{j}$; and $\omega_{j}=\sum_{t=1}^{\# h_{\omega_{j}}\left(p_{\omega_{j}}\right)} p_{\omega_{j}}^{t} h_{\omega_{j}}^{t}\left(p_{\omega_{j}}^{t}\right)$.

Step 3: work out the transformed probability weight function $\pi_{i k j}\left(\omega_{j}^{\prime}\right)$ according to the weighting function of PT:

$$
\pi_{i k j}\left(\omega_{j}^{\prime}\right)= \begin{cases}\pi_{i k j}^{+}\left(\omega_{j}^{\prime}\right)=\frac{\omega_{j}^{\prime \gamma}}{\left(\left(\omega_{j}^{\prime}\right)+\left(1-\omega_{j}^{\prime}\right)^{\gamma}\right)^{1 / \gamma}}, & h_{i j}^{\prime}\left(p_{i j}^{\prime}\right) \geq h_{k j}^{\prime}\left(p_{k j}^{\prime}\right), \\ \pi_{i k j}^{-}\left(\omega_{j}^{\prime}\right)=\frac{\omega_{j}^{\prime \delta}}{\left(\omega_{j}^{\prime}+\left(1-\omega_{j}^{\prime}\right)^{\delta}\right)^{1 / \delta},} & h_{i j}^{\prime}\left(p_{i j}^{\prime}\right)<h_{k j}^{\prime}\left(p_{k j}^{\prime}\right),\end{cases}
$$


where the comparison between $h_{i j}^{\prime}\left(p_{i j}^{\prime}\right)$ and $h_{k j}^{\prime}\left(p_{k j}^{\prime}\right)$ is determined by using equations (12) and (13).

Step 4: acquire the relative weight $\pi_{i k j^{*}}$ of $A_{i}$ over $A_{k}$ :

$$
\pi_{i k j^{*}}=\frac{\pi_{i k j}\left(\omega_{j}^{\prime}\right)}{\pi_{i k r}\left(\omega_{r}^{\prime}\right)}, \quad r, j \in M, \forall(i, k)
$$

where $\pi_{i k r}\left(\omega_{r}^{\prime}\right)=\max \left(\pi_{i k j}\left(\omega_{j}^{\prime}\right) \mid j \in M\right)$ and $\pi_{i k r}\left(\omega_{r}^{\prime}\right)$ is named as the reference criterion.

Step 5: calculate the relative prospect dominance degrees $\varphi_{j^{*}}\left(A_{i}, A_{k}\right)$ of the alternative $A_{i}$ over $A_{k}$ under the criterion $c_{j}$ as follows:

When $c_{j}$ is the benefit criterion, the relative prospect dominance degree is $\varphi_{j^{*}}^{B}\left(A_{i}, A_{k}\right)$ :

$$
\varphi_{j^{*}}^{B}\left(A_{i}, A_{k}\right)= \begin{cases}\frac{\pi_{i k j^{*}}\left(d\left(h_{i j^{*}}^{\prime}\left(p_{i j^{*}}^{\prime}\right), h_{k j^{*}}^{\prime}\left(p_{k j^{*}}^{\prime}\right)\right)\right)^{\alpha}}{\sum_{j^{*}=1}^{m} \pi_{i k j^{*}}}, & h_{i j^{*}}^{\prime}\left(p_{i j^{*}}^{\prime}\right)>h_{k j^{*}}^{\prime}\left(p_{k j^{*}}^{\prime}\right), \\ 0, & h_{i j^{*}}^{\prime}\left(p_{i j^{*}}^{\prime}\right)=h_{k j^{*}}^{\prime}\left(p_{k j^{*}}^{\prime}\right), \\ \frac{-\lambda\left(\sum_{j^{*}=1}^{m} \pi_{i k j^{*}}\right)\left(d\left(h_{i j^{*}}^{\prime}\left(p_{i j^{*}}^{\prime}\right), h_{k j^{*}}^{\prime}\left(p_{k j^{*}}^{\prime}\right)\right)\right)^{\beta}}{\pi_{i k j^{*}}}, & h_{i j^{*}}^{\prime}\left(p_{i j^{*}}^{\prime}\right)<h_{k j^{*}}^{\prime}\left(p_{k j^{*}}^{\prime}\right) .\end{cases}
$$

When $c_{j}$ is the cost criterion, the relative prospect dominance degree is $\varphi_{j^{*}}^{C}\left(A_{i}, A_{k}\right)$ :

$$
\varphi_{j^{*}}^{C}\left(A_{i}, A_{k}\right)= \begin{cases}\frac{-\lambda\left(\sum_{j^{*}=1}^{m} \pi_{i k j^{*}}\right)\left(d\left(h_{i j^{*}}^{\prime}\left(p_{i j^{*}}^{\prime}\right), h_{k j^{*}}^{\prime}\left(p_{k j^{*}}^{\prime}\right)\right)\right)^{\beta}}{\pi_{i k j^{*}}}, & h_{i j^{*}}^{\prime}\left(p_{i j^{*}}^{\prime}\right)>h_{k j^{*}}^{\prime}\left(p_{k j^{*}}^{\prime}\right), \\ 0, & h_{i j^{*}}^{\prime}\left(p_{i j^{*}}^{\prime}\right)=h_{k j^{*}}^{\prime}\left(p_{k j^{*}}^{\prime}\right), \\ \frac{\pi_{i k j^{*}}\left(d\left(h_{i j^{*}}^{\prime}\left(p_{i j^{*}}^{\prime}\right), h_{k j^{*}}^{\prime}\left(p_{k j^{*}}^{\prime}\right)\right)\right)^{\alpha}}{\sum_{j^{*}=1}^{m} \pi_{i k j^{*}}}, & h_{i j^{*}}^{\prime}\left(p_{i j^{*}}^{\prime}\right)<h_{k j^{*}}^{\prime}\left(p_{k j^{*}}^{\prime}\right),\end{cases}
$$

where $\alpha, \beta$, and $\lambda$ are the parameters of $\mathrm{PT}$; $d\left(h_{i j^{*}}^{\prime}\left(p_{i j^{*}}^{\prime}\right), h_{k j^{*}}^{\prime}\left(p_{k j^{*}}^{\prime}\right)\right)$ is the corresponding distance calculated by using equation (14).

Step 6: obtain the prospect dominance degrees based on equation (7):

$$
\psi\left(A_{i}, A_{k}\right)=\sum_{j^{*}=1}^{m} \varphi_{j}^{*}\left(A_{i}, A_{k}\right), \quad \forall(i, k) .
$$

Step 7: calculate the overall prospect dominance degrees from equation (9):

$$
\Omega\left(A_{i}\right)=\frac{\sum_{k=1}^{n} \psi\left(A_{i}, A_{k}\right)-\min _{i}\left\{\sum_{k=1}^{n} \psi\left(A_{i}, A_{k}\right)\right\}}{\max _{i}\left\{\sum_{k=1}^{n} \psi\left(A_{i}, A_{k}\right)\right\}-\min _{i}\left\{\sum_{k=1}^{n} \psi\left(A_{i}, A_{k}\right)\right\}}, \quad \forall i, k \in N .
$$


The bigger the $\Omega\left(A_{i}\right)$ is, the better the alternative $A_{i}$ will be.

3.3. Procedure of the Novel TODIM with Hesitant Fuzzy Information. Hesitant fuzzy information is represented by HFS [34] and is used to describe the situation that the DMs hesitate between several different values, and each hesitation value is equally important. In fact, it also can be expressed as a special form of probabilistic hesitant fuzzy information. When the probabilities are equal, probabilistic hesitant fuzzy information turns into hesitant fuzzy information. The HFS can be denoted as $\left.H=\left\{<x_{i}, h_{x_{i}}\right\rangle \mid x_{i} \in X\right\}, \quad$ and $\quad h_{x_{i}}=\left\{h_{x_{i}}^{t} \mid t=1,2\right.$, $\left.\ldots, \# h_{x_{i}}\right\}$ is called a hesitant fuzzy element (HFE). To demonstrate the effectiveness of the proposed method in Section 3.2, we further combine the novel TODIM with hesitant fuzzy information in this section. The process is shown as follows:

Step 1: obtain the original information matrix and weight information:

$$
\begin{aligned}
& Y=\left(\begin{array}{ccc}
h_{11} & \cdots & h_{1 m} \\
\vdots & \ddots & \vdots \\
h_{n 1} & \cdots & h_{n m}
\end{array}\right)=\left(h_{i j}\right)_{n \times m}, \\
& \omega=\left(h_{\omega_{1}}, h_{\omega_{2}}, \ldots, h_{\omega_{m}}\right),
\end{aligned}
$$

where $i \in N, j \in M$; $h_{i j}$ is the evaluation information of the alternative $A_{i}$ over the criterion $c_{j}$; and $h_{\omega_{j}}$ is the weighting information of $c_{j}$.

Step 2: normalize the weight information based on the following equation:

$$
\omega_{j}^{\prime}=\frac{\omega_{j}}{\sum_{j=1}^{m} \omega_{j}},
$$

where $\omega_{j}=\rho\left(h_{\omega_{j}}\right)$ and $\rho\left(h_{\omega_{j}}\right)$ is the score function (32) of the HFE $h_{\omega_{j}}$ :

$$
\rho(h)=\frac{1}{\# h} \sum_{t=1}^{\# h} h^{t} .
$$

Step 3: obtain the transformed probability weight function $\pi_{i k j}\left(\omega_{j}^{\prime}\right)$ according to the following equation:

$\pi_{i k j}\left(\omega_{j}^{\prime}\right)= \begin{cases}\pi_{i k j}^{+}\left(\omega_{j}^{\prime}\right)=\frac{\omega_{j}^{\prime \gamma}}{\left(\omega_{j}^{\prime} \gamma+\left(1-\omega_{j}^{\prime}\right)^{\gamma}\right)^{1 / \gamma}}, & h_{i j}^{\prime} \geq h_{k j}^{\prime}, \\ \pi_{i k j}^{-}\left(\omega_{j}^{\prime}\right)=\frac{\omega_{j}^{\prime \delta}}{\left(\omega_{j}^{\prime}+\left(1-\omega_{j}^{\prime}\right)^{\delta}\right)^{1 / \delta}}, & h_{i j}^{\prime}<h_{k j}^{\prime},\end{cases}$

where the comparison of the HFEs $h_{i j}^{\prime}$ and $h_{k j}{ }^{\prime}$ is decided by the score function (equation (32)) and the deviation function (the following equation) of the HFEs:

$$
\sigma(h)=\frac{1}{\# h} \sqrt{\sum_{\forall_{h^{t}} \in h}\left(h^{t}-\rho(h)\right)^{2}} .
$$

The detailed rules are represented as follows:

(1) If $\rho\left(h_{i j}^{\prime}\right)>\rho\left(h_{k j}^{\prime}\right)$, then $h_{i j}^{\prime}>h_{k j}^{\prime}$

(2) If $\rho\left(h_{i j}^{\prime}\right)<\rho\left(h_{k j}^{\prime}\right)$, then $h_{i j}^{\prime}<h_{k j}^{\prime}$

(3) If $\rho\left(h_{i j}^{\prime}\right)=\rho\left(h_{k j}^{\prime}\right)$, then

(1) If $\sigma\left(h_{i j}^{\prime}\right)>\sigma\left(h_{k j}{ }^{\prime}\right)$, then $h_{i j}^{\prime}<h_{k j}^{\prime}$

(2) If $\sigma\left(h_{i j}^{\prime}\right)<\sigma\left(h_{k j}^{\prime}\right)$, then $h_{i j}^{\prime}>h_{k j}^{\prime}$

(3) If $\sigma\left(h_{i j}^{\prime}\right)=\sigma\left(h_{k j}^{\prime}\right)$, then $h_{i j}^{\prime}=h_{k j}^{\prime}$

Step 4: calculate the relative weight $\pi_{i k j^{\prime}}$ based on equation (24) and the transformed probability weight $\pi_{i k j}\left(\omega_{j}^{\prime}\right)$

Step 5: work out the relative prospect dominance degrees $\varphi_{j^{\prime}}\left(A_{i}, A_{k}\right)$ of the alternatives $A_{i}$ over $A_{k}$ under the criterion $c_{j}$ as follows:

When $c_{j}$ is the benefit criterion, the relative prospect dominance degree is $\varphi_{j^{\prime}}^{B}\left(A_{i}, A_{k}\right)$ :

$$
\varphi_{j^{\prime}}^{B}\left(A_{i}, A_{k}\right)= \begin{cases}\frac{\pi_{i k j^{\prime}}\left(d\left(h_{i j^{\prime}}^{\prime}, h_{k j^{\prime}}^{\prime}\right)\right)^{\alpha}}{\sum_{j^{\prime}=1}^{m} \pi_{i k j^{\prime}}}, & h_{i j^{\prime}}^{\prime}>h_{k j^{\prime}}^{\prime}, \\ 0, & h_{i j^{\prime}}^{\prime}=h_{k j^{\prime}}^{\prime}, \\ -\frac{\lambda\left(\sum_{j^{\prime}=1}^{m} \pi_{i k j^{\prime}}\right)\left(d\left(h_{i j^{\prime}}^{\prime}, h_{k j^{\prime}}^{\prime}\right)\right)^{\beta}}{\pi_{i k j^{\prime}}}, & h_{i j^{\prime}}^{\prime}<h_{k j^{\prime}}^{\prime} .\end{cases}
$$


When $c_{j}$ is the cost criterion, the relative prospect dominance degree is $\varphi_{j^{\prime}}^{C}\left(A_{i}, A_{k}\right)$ :

$$
\vartheta_{j^{\prime}}^{C}\left(A_{i}, A_{k}\right)= \begin{cases}-\frac{\lambda\left(\sum_{j^{\prime}=1}^{m} \pi_{i k j^{\prime}}\right)\left(d\left(h_{i j^{\prime}}^{\prime}, h_{k j^{\prime}}^{\prime}\right)\right)^{\beta}}{\pi_{i k j^{\prime}}}, & h_{i j^{\prime}}^{\prime}>h_{k j^{\prime}}^{\prime}, \\ 0, & h_{i j^{\prime}}^{\prime}=h_{k j^{\prime}}^{\prime}, \\ \frac{\pi_{i k j^{\prime}}\left(d\left(h_{i j^{\prime}}^{\prime}, h_{k j^{\prime}}^{\prime}\right)\right)^{\alpha}}{\sum_{j^{\prime}=1}^{m} \pi_{i k j^{\prime}}}, & h_{i j^{\prime}}^{\prime}<h_{k j^{\prime}}^{\prime},\end{cases}
$$

where $\lambda$ denotes the attenuation factor of the losses and $d\left(h_{i j^{\prime}}^{\prime}, h_{k j^{\prime}}^{\prime}\right)$ is the corresponding distance calculated by

$$
d\left(h_{i j}, h_{k j}\right)=\frac{1}{\# h_{i j}} \sum_{t=1}^{\# h_{i j}}\left|h_{i j}^{t}-h_{k j}^{t}\right|, \quad \# h_{i j}=\# h_{k j} .
$$

Step 5: acquire the prospect dominance degrees based on equation (27).

Step 6: calculate the overall dominance degrees according to equation (28), and the bigger the $\Omega\left(A_{i}\right)$ is, the better the alternative $A_{i}$ will be.

From the procedures above, the novel TODIM with probabilistic hesitant fuzzy information and the novel TODIM with hesitant fuzzy information are given in Sections 3.2 and 3.3, respectively. It is worth noting that in the proposed methods, the original weight information is represented by P-HFE and HFE according to (20) and (30) respectively. Moreover, the score function is used to represent the weight information of (22) and (31), which is inspired from [37]. Indeed, the score function is an excellent tool that reflects the comprehensive information of a piece of the evaluation for the alternative, and it is also good at grasping the basic information. Therefore, we also use the score function to complete the weight transformation in this paper. Besides, both these methods conform to the original PT by modifying the perceived probability weighting function and the difference of the risk attitudes for gains and losses. Concerning the ability to express the information of DMs, the novel TODIM with probabilistic hesitant fuzzy information has more advantages in describing different hesitant degrees of the hesitant values by using possibilities. The novel TODIM with hesitant fuzzy information is used to carry out a series of convincing comparisons. Actually, it is regarded as a particular form of the former method when the probability is equal. Hence, the novel TODIM with probabilistic hesitant fuzzy information is our main focus in this paper, and we believe that it can reflect more evaluation information than the novel TODIM with hesitant fuzzy information. Then, a case study is carried out to show the application of the proposed methods.

3.4. Theoretical Analysis of the Proposed Method. It is critical to know the advantages of the proposed method which helps us to understand the MCDM process and at the same time contributes to analyzing the ranking results reasonably. The theoretical superiority of combining the novel TODIM with probabilistic hesitant fuzzy information can be concluded from the two aspects: information distortion and information attenuation. In terms of information distortion, the proposed method has modified three inconsistencies of classical TODIM with PT. First, this method reflects the actual meaning of parameters compared with the method proposed by Krohling and Souza [9] and Peng et al. [12], and their dominance functions are equations (15) and (16), respectively. Although the values of $\alpha$ and $\beta$ are equal under this circumstance, their meanings are completely different, and their values may be different in different experiments. $\alpha$ indicates the concavity of the power function for gains, while $\beta$ represents the convexity case for losses. It is improper to depict those two different states with only one uniform parameter $k$, which may lead to information distortion. The proposed method has also made the second measure to avoid information distortion, and it is the use of weight function compared with the method proposed in [36] and its dominance function shown as equation (17). The weight function is important in PT because it modifies an easily overlooked situation that people tend to overestimate low probability events and underestimate high probability events. Third, the most important point revealed by the proposed method and neglected by most existing studies is that the $\alpha$ and $\beta$ only appear in the value function and work on gains and losses according to the original PT.

The novel TODIM does compensate for some shortcomings of the traditional TODIM by reflecting the actual meaning of parameters, considering the transformed weight function and modifying its core idea referring to the original PT. However, the information attenuation is inevitable when the novel TODIM is explained by crisp number [32]. In some practical situations, the DMs could not give an accurate assessment and usually hesitant in several assessments. This situation can be well simulated by hesitant fuzzy information. But hesitant fuzzy information could not reflect the different preferences for every possible value. Probabilistic hesitant fuzzy information can describe different preferences for each possible value with probabilities, so the performance of the novel TODIM with probabilistic hesitant fuzzy information will be superior to the one with scrip number and the one with hesitant fuzzy information. For example, if a person is invited to evaluate a suitable supplier of electric vehicle charging piles in the urban planning, he/she is not very sure about the score and hesitates between several values 81,85 , and 90. Furthermore, among those three values, he/she prefers 81 , and he/she thinks there is 0.7 probability of 81 and 0.2 and 0.1 probabilities of 85 and 90, respectively. In this situation, the evaluation information can be interpreted as $\{81(0.7), 85(0.2), 90(0.1)\}$ by probabilistic hesitant fuzzy information. While using hesitant fuzzy information, this situation is only interpreted as $\{81,85$, $90\}$, which could not reflect the preference of DM. In addition, probabilistic hesitant fuzzy information can reflect the opinions of DMs in group decision-making. For instance, when five experts were invited, they need to give their opinions. If one expert gives 70 , the other three of them assign 83 , and only one expert gives 91; the evaluation information will be expressed as $\{70(0.2), 83(0.6), 91(0.2)\}$ in the form of probabilistic hesitant fuzzy information. If hesitant fuzzy information is used, the 
evaluation information will be $\{70,83,91\}$. Obviously, the use of hesitant fuzzy information sometimes leads to information loss. Furthermore, the information attenuation will be amplified when the gap between these evaluation values is large. Hence, considering the limitations of hesitant fuzzy information in expressing the idea of individuals and in collecting ideas of a group, probabilistic hesitant fuzzy information is more suitable to describe the uncertainties of DMs.

From the theoretical analysis above, the novel TODIM with probabilistic hesitant fuzzy information has more advantages than the one with crisp number or the one with hesitant fuzzy information. It eases information distortion by adjusting itself to the original PT and avoids information attenuation by using probabilistic hesitant fuzzy information. The superiority of the proposed method is theoretically illustrated. Then, an illustrative example is given to show its advantages in further detail and to enhance the understanding of the proposed method.

\section{Illustrative Example}

This section presents an electric bus bid case with four different methods. They are the extension of two types of different fuzzy information including probabilistic hesitant fuzzy information and hesitant fuzzy information.

4.1. Background of the Case. With the development of new energy technologies, electric buses have become one of the most mature areas of new energy vehicle applications. Electric bus is clean, low noise, and environmental protection, which greatly enhances the user's experience. It has been reported by Bloomberg that the U.S. has a fleet of 300 electric buses, while China has 421,000 by the end of 2018
[38]. Besides, it has been estimated that more than 385,000 electric buses have been put into services, accounting for $17 \%$ of the total national bus fleet [39].

With the promotion of ecological civilization strategy, the Chinese government has put forward higher requirements for the application of green energy. It is estimated that by 2020 , the number of new energy vehicles used in urban public transportation will reach 600,000 . In other words, more electric clean buses are needed to deploy sustainable development strategy in more cities. Evidently, the most important step is to select a dependent new energy vehicle supplier. Investment $[40,41]$ plays an important role in this process. As a well-known public transportation company in Shanghai, China, Shanghai Pudong New Area Public Transport Investment Development Company mainly engaged in urban transportation and vehicle maintenance. It has announced a procurement project to purchase more electric public transportation buses in September 6, 2019 [41]. After the preliminary bid screening, there are four qualified suppliers left: $A_{1}, A_{2}, A_{3}$, and $A_{4}$. The final round of bidding aims to select the most appropriate green supplier. Selection experts concern the following aspects: safety $\left(c_{1}\right)$, environment $\left(c_{2}\right)$, economy $\left(c_{3}\right)$, and convenience cost $\left(c_{4}\right)$, and all the four criteria belong to the benefit ones.

\subsection{Screening Process of the Novel TODIM with Probabilistic Hesitant Fuzzy Information}

Step 1: to better distinguish the probability in the evaluation information from the membership degree, it is magnified by 100 times. Then, the evaluation information is given as follows:

$$
\begin{aligned}
& c_{1} \quad c_{2} \\
& A_{1}(\{55(0.22), 68(0.51), 73(0.27)\}\{60(0.45), 66(0.39), 70(0.16)\} \\
& Y=\begin{array}{l}
A_{2} \\
A_{3} \\
A_{4}
\end{array}\left\{\begin{array}{lll}
\{63(0.32), 71(0.48), 77(0.2)\} & \{66(0.39), 71(0.52), 77(0.09)\} \\
\{67(0.49), 72(0.44), 75(0.07)\} & \{62(0.58), 69(0.3), 74(0.12)\}
\end{array}\right. \\
& \omega=(\{0.34(0.68), 0.40(0.32)\},\{0.09(0.39), 0.11(0.61)\},\{0.19(0.56), 0.22(0.44)\},\{0.21(0.43), 0.27(0.57)\}) .
\end{aligned}
$$

Step 2: normalize the evaluation matrix of the four green suppliers and get the normalized weight information at the same time:

$$
\begin{aligned}
& \begin{array}{cccc}
c_{1} & c_{2} & c_{3} & c_{4}
\end{array}
\end{aligned}
$$

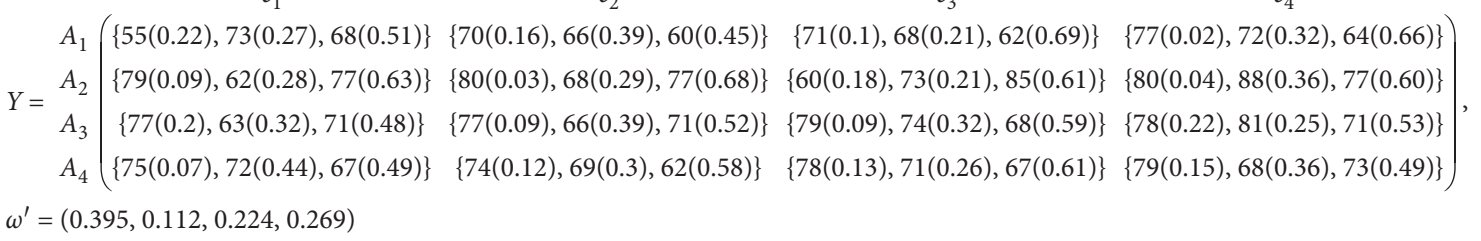


Step 3: calculate the transformed probability weights according to equation (23), and the results are shown in Table 2.

Step 4: obtain the relative weights according to equation (24), and the results are shown in Table 3.

Step 5: work out the relative prospect dominance degrees of the alternative $A_{1}$ over the others under each criterion, which is determined by using equations (25) and (26), shown in Table 4.

Step 6: obtain the prospect dominance degrees of the alternative $A_{i}$ over the others by using equation (27), shown in Table 5.

Step 7: the overall prospect dominance degrees of each alternative is calculated by using equation (28), and the results are exhibited in Table 6.

Step 8: since $\Omega\left(A_{2}\right)>\Omega\left(A_{3}\right)>\Omega\left(A_{4}\right)>\Omega\left(A_{1}\right)$, there exists $A_{2}>A_{3}>A_{4}>A_{1}$. The company $A_{2}$ should be selected in this bid.
4.3. Screening Process of the Extended TODIM with Probabilistic Hesitant Fuzzy Information

Step 1: the normalized evaluation matrix is transformed in the same way as shown in Step 1 and Step 2 in Section 4.2 .

Step 2: calculate the relative weight of each criterion based on (6), shown in Table 7.

Step 3: obtain the relative dominance degrees $\varphi_{j}\left(A_{i}, A_{k}\right)$ of the alternative $A_{i}$ over $A_{k}$ under the criterion $c_{j}$ as follows, and the result is exhibited in Table 8 , and $\varphi_{j}\left(A_{i}, A_{i}\right)=0$ is not shown in this table: When $c_{j}$ is the benefit criterion, the relative prospect dominance degree is

$$
\varphi_{j}^{B}\left(A_{i}, A_{k}\right)= \begin{cases}\sqrt{\frac{\omega_{j r}^{\prime}}{\sum_{j=1}^{m} \omega_{j r}^{\prime}} d\left(h_{i j}^{\prime}\left(p_{i j}^{\prime}\right), h_{k j}^{\prime}\left(p_{k j}^{\prime}\right)\right),} & h_{i j}^{\prime}\left(p_{i j}^{\prime}\right)>h_{k j}^{\prime}\left(p_{k j}^{\prime}\right), \\ 0, & h_{i j}^{\prime}\left(p_{i j}^{\prime}\right)=h_{k j}^{\prime}\left(p_{k j}^{\prime}\right), \\ -\frac{1}{\lambda} \sqrt{\frac{\sum_{j=1}^{m} \omega_{j r}^{\prime}}{\omega_{j r}^{\prime}} d\left(h_{i j}^{\prime}\left(p_{i j}^{\prime}\right), h_{k j}^{\prime}\left(p_{k j}^{\prime}\right)\right),} & h_{i j}^{\prime}\left(p_{i j}^{\prime}\right)<h_{k j}^{\prime}\left(p_{k j}^{\prime}\right) .\end{cases}
$$

When $c_{j}$ is the cost criterion, the relative prospect

dominance degree is

$$
\varphi_{j}^{C}\left(A_{i}, A_{k}\right)= \begin{cases}-\frac{1}{\lambda} \sqrt{\frac{\sum_{j=1}^{m} \omega_{j r}^{\prime}}{\omega_{j r}^{\prime}} d\left(h_{i j}^{\prime}\left(p_{i j}^{\prime}\right), h_{k j}^{\prime}\left(p_{k j}^{\prime}\right)\right),} & h_{i j}^{\prime}\left(p_{i j}^{\prime}\right)>h_{k j}^{\prime}\left(p_{k j}^{\prime}\right), \\ 0, & h_{i j}^{\prime}\left(p_{i j}^{\prime}\right)=h_{k j}^{\prime}\left(p_{k j}^{\prime}\right), \\ \sqrt{\frac{\omega_{j r}^{\prime}}{\sum_{j=1}^{m} \omega_{j r}^{\prime}} d\left(h_{i j}^{\prime}\left(p_{i j}^{\prime}\right), h_{k j}^{\prime}\left(p_{k j}^{\prime}\right)\right),} & h_{i j}^{\prime}\left(p_{i j}^{\prime}\right)<h_{k j}^{\prime}\left(p_{k j}^{\prime}\right),\end{cases}
$$

where $d\left(h_{i j}^{\prime}\left(p_{i j}^{\prime}\right), h_{k j}^{\prime}\left(p_{k j}^{\prime}\right)\right)$ is the distance of $h_{i j}^{\prime}\left(p_{i j}^{\prime}\right)$ and $h_{k j}^{\prime}\left(p_{k j}^{\prime}\right)$.
Step 4: the prospect dominance degrees of the alternative $A_{i}$ over the others under each criterion are 
determined by using equation (27). The result is exhibited in Table 9 , and $\psi_{j}\left(A_{i}, A_{i}\right)=0$ is not shown in this table.

Step 5: the overall dominance degrees of each alternative are calculated by using equation (28), and the results are exhibited in Table 10.

Step 6: since $\Omega\left(A_{2}\right)>\Omega\left(A_{3}\right)>\Omega\left(A_{4}\right)>\Omega\left(A_{1}\right)$, we can get $A_{2}>A_{3}>A_{4}>A_{1}$. The company $A_{2}$ should be selected in this bid.

\subsection{Screening Process of the Novel TODIM with Hesitant Fuzzy Information}

Step 1: obtain the evaluation matrix and the weight information as hesitant fuzzy information:

$$
\begin{aligned}
& \begin{array}{ccccc}
c_{1} & c_{2} & c_{3} & c_{4}
\end{array} \\
& x_{1}(\{55,68,73\}\{60,66,70\}\{62,68,71\}\{64,72,77\} \\
& Y=\begin{array}{l|lllll}
x_{2} & \{62,77,79\} & \{68,77,80\} & \{60,73,85\} & \{77,80,88\} \\
x_{3} & \{63,71,77\} & \{66,71,77\} & \{68,74,79\} & \{71,78,81\} \\
& x_{4} & \{67,72,75\} & \{62,69,74\} & \{67,71,78\} & \{68,73,79\}
\end{array}, \text {, } \\
& \omega=(\{0.34,0.40\},\{0.09,0.11\},\{0.19,0.22\},\{.21,0.27\}) .
\end{aligned}
$$

Step 2: normalize the evaluation matrix. The normalized evaluation information matrix is the same as (42). Besides, the normalized weight information is based on equation (31).

Step 3: obtain the transformed probability weights by using equation (33), and the results are shown in Table 11. The comparison of the two HFEs $h_{i j}^{\prime}$ and $h_{k j}^{\prime}$ is determined by the score function (equation (32)) and the deviation function (equation (34)).

Step 4: obtain the relative weight of $A_{i}$ over $A_{k}$ based on equation (24).

Step 5: calculate the relative prospect dominance degrees $\varphi_{j}^{*}\left(A_{i}, A_{k}\right)$ of the alternative $A_{i}$ over $A_{k}$ under the criterion $c_{j}$. When $c_{j}$ is the benefit criterion, the relative prospect dominance degree is calculated by using equation (35). Otherwise, the relative prospect dominance degree is calculated by using equation (36). The results are exhibited in Table 12.

Step 6: obtain the dominance degrees of the alternative $A_{i}$ over the others by using equation (27).

Step 7: obtain the overall dominance degrees according to equation (28), shown in Table 13.

Step 8: since $\Omega\left(A_{2}\right)>\Omega\left(A_{3}\right)>\Omega\left(A_{4}\right)>\Omega\left(A_{1}\right)$, we can get $A_{2}>A_{3}>A_{4}>A_{1}$. Thus, the company $A_{2}$ should be selected in this bid.

\subsection{Screening Process of the Extended TODIM with Hesitant Fuzzy Information}

Step 1: obtain the evaluation matrix and the weight information as hesitant fuzzy information. They are the same as the information shown in (42) and (43), respectively.

Step 2: calculate relative weights, and the results are shown in Table 14:

$$
\omega_{j r}=\frac{\omega_{j}}{\omega_{r}}=\frac{\rho\left(h_{\omega_{j}}\right)}{\rho\left(h_{\omega_{r}}\right)},
$$

where $j, r \in M, \rho\left(h_{\omega_{j}}\right)$ is the score function shown in (32).

Step 3: calculate the relative dominance degrees $\varphi_{j}\left(A_{i}, A_{k}\right)$ of the alternative $A_{i}$ over $A_{k}$ under the criterion $c_{j}$ as follows, and the results are exhibited in Table 15:

When $c_{j}$ is the benefit criterion, the relative dominance degree is

$$
\varphi_{j}^{B}\left(A_{i}, A_{k}\right)= \begin{cases}\sqrt{\frac{\omega_{j r}}{\sum_{j=1}^{m} \omega_{j r}} d\left(h_{i j}, h_{k j}\right)}, & h_{i j}>h_{k j}, \\ 0, & h_{i j}=h_{k j}, \\ -\frac{1}{\lambda} \sqrt{\frac{\sum_{j=1}^{m} \omega_{j r}}{\omega_{j r}} d\left(h_{i j}, h_{k j}\right),} & h_{i j}<h_{k j} .\end{cases}
$$

When $c_{j}$ is the cost criterion, the relative dominance degree is

$$
\varphi_{j}^{C}\left(A_{i}, A_{k}\right)= \begin{cases}-\frac{1}{\lambda} \sqrt{\frac{\sum_{j=1}^{m} \omega_{j r}}{\omega_{j r}} d\left(h_{i j}, h_{k j}\right),} & h_{i j}>h_{k j}, \\ 0, & h_{i j}=h_{k j}, \\ \sqrt{\frac{\omega_{j r}^{m}}{\sum_{j=1}^{m} \omega_{j r}}\left(h_{i j}, h_{k j}\right)}, & h_{i j}<h_{k j},\end{cases}
$$

where $d\left(h_{i j}, h_{k j}\right)$ is the distance of hesitant fuzzy information $h_{i j}$ and $h_{k j}$.

Step 4: obtain the dominance degrees of the alternative $A_{i}$ over the others by using equation (27), shown in Table 16.

Step 5: obtain the overall dominance degrees by using equation (28), shown in Table 17.

Step 6: since $\Omega\left(A_{2}\right)>\Omega\left(A_{3}\right)>\Omega\left(A_{4}\right)>\Omega\left(A_{1}\right)$, we can get $A_{2}>A_{3}>A_{4}>A_{1}$. Thus, the company $A_{2}$ should be selected in this bid. 
4.6. Analysis. In this section, we summarize the results of the above decision-making processes and display them in Table 18. By comparing the results of these four methods, the preponderance of combining the novel TODIM with probabilistic hesitant fuzzy information is fully illustrated.

From Table 18, the same ranking results $\left(A_{2}>A_{3}>A_{4}>A_{1}\right)$ are presented from the four kinds of methods. Obviously, the company $A_{2}$ is considered to be the optimal choice, and the company $A_{1}$ is the worst choice. However, there are huge differences in the value of overall prospect dominance degrees obtained by the four methods.

Based on Table 18 and Figure 1, compared with Method 1 and Method 2, as well as Method 3 and Method 4, the difference of overall prospect dominance degrees between the alternatives $A_{3}$ and $A_{4}$, which use the novel TODIM based on PT, is greater than the extended one. We attribute this phenomenon to the different risk attitudes of the DMs concerning about gains and losses which are considered in PT. Compared with Method 1 and Method 3, as well as Method 2 and Method 4, we can discover that the overall prospect dominance degrees obtained from the methods, which adopt probabilistic hesitant fuzzy information and concern different preference degrees of hesitant values, are smaller than those obtained from hesitant fuzzy information. We contribute this phenomenon in reflecting more details of DMs are produced by using the probabilistic fuzzy information. The result also illustrates that probabilistic hesitant fuzzy information is good at expressing the DMs' evaluation information and different preferences for hesitant fuzzy values. Therefore, we believe the novel TODIM with probabilistic hesitant fuzzy information is more comprehensive and effective in decision-making.

\section{Comparative Analysis}

To better illustrate the effectiveness of the proposed method, we carry out the comparative analysis with TOPSIS, sensitivity analysis, and simulation analysis. The results of the analyses strongly support the superiority of the developed method.

5.1. Comparative Analysis with TOPSIS. Analysis in Section 4.6 focuses on comparing the different extensions of TODIM with different fuzzy information. In this section, to illustrate the advantages of TODIM with probabilistic hesitant fuzzy information, we compare it with TOPSIS under probabilistic hesitant fuzzy environment. It offers a more convincing analysis because this does not focus on the psychological factor of DMs. Motivated by $\mathrm{He}$ and $\mathrm{Xu}$ [43] and Dagdeviren et al. [44], probabilistic hesitant fuzzy information is extended to TOPSIS. By applying the example in Section 4, we use this method to obtain the best alternative.

First, we obtain the normalized evaluation matrix which is the same as the matrix of Step 2 in Section 4.2. Second, we find the positive ideal alternative $A^{+}$which is the alternative with the closest distance to ideal solution and the negative ideal alternative $A^{-}$which is farthest to the ideal solution by using equations (49) and (50) based on each criterion. The results are presented in Table 19:

$$
\begin{aligned}
& A^{+}=\left\{h_{1}^{+}, h_{2}^{+}, \ldots, h_{j}^{+}\right\}=\left\{\max _{i} h_{i j} \mid i=1,2, \ldots, n\right\}, \\
& A^{-}=\left\{h_{1}^{-}, h_{2}^{-}, \ldots, h_{j}^{-}\right\}=\left\{\max _{i} h_{i j} \mid i=1,2, \ldots, n\right\} .
\end{aligned}
$$

Then, we use equations (49) and (50) to compute the distances between the alternative and the ideal solution, where the distance measures are obtained by using equation (14), and the results are shown in Table 20:

$$
\begin{aligned}
& D_{i}^{+}=\sum_{j=1}^{m} w_{j} d\left(h_{i j}\left(p_{i j}\right), h_{i}^{+}\right), \\
& D_{i}^{-}=\sum_{j=1}^{m} w_{j} d\left(h_{i j}\left(p_{i j}\right), h_{i}^{-}\right) .
\end{aligned}
$$

We can easily obtain the relative closeness coefficients of each alternative by using equation (51). They are listed in Table 21. Hence, the ranking of the alternatives obtained from TOPSIS with probabilistic hesitant fuzzy information is $A_{2}>A_{4}>A_{3}>A_{1}$ :

$$
C_{i}^{*}=\frac{D_{i}^{-}}{D_{i}^{+}+D_{i}^{-}}, \quad i=1,2, \ldots, n .
$$

The superiority of the proposed method can be seen from the results shown in Tables 18 and 21. The ranking result obtained from the TOPSIS method is different from the one obtained from the novel TODIM with probabilistic hesitant fuzzy information, and the ranking result of the middle two alternatives $\left(A_{3}\right.$ and $\left.A_{4}\right)$ is different in those two methods. This distinction can be attributed to the following reasons, which are also the advantages of the proposed method. First, the novel TODIM has identified more information on DMs. It not only involves the transformed probability weight but also considers the difference between every two alternatives, instead of focusing on the difference between the alternative and the positive ideal solution or the negative ideal solution shown in TOPSIS. In addition, TOPSIS with probabilistic hesitant fuzzy information does not reflect the psychological factors of DMs, while probabilistic hesitant fuzzy information describes the uncertain evaluation information, and all participants usually are bounded rational in real decision-making situations. This defect is fully compensated in the TODIM by considering the risk attitudes for gains and losses, which makes the results more accurate, objective, and more consistent with practical experience.

By addressing the comparison of the existing method, the demand for combining probabilistic hesitant fuzzy information with TODIM has also been fully demonstrated. The overall prospect dominance degrees of TODIM and the relative closeness coefficients of the TOPSIS with probabilistic hesitant fuzzy environment are much smaller than the results of TODIM with hesitant fuzzy information. It is strongly proven that the probabilistic hesitant fuzzy information has discerned and reflected more information of DMs. Therefore, probabilistic hesitant fuzzy information is an effective tool to express a wider range of uncertain information in the decision-making process. 


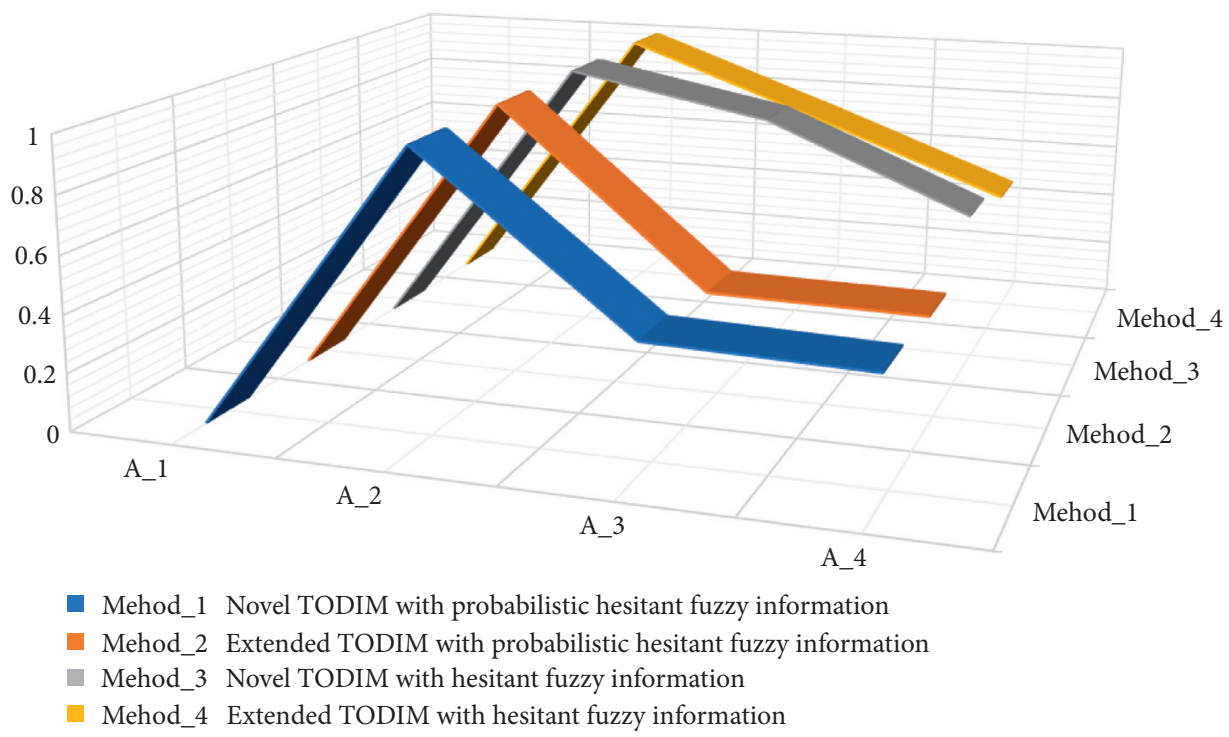

FIGURE 1: Overall prospect dominance degrees.

TABLE 19: The positive ideal solution and negative ideal solution.

\begin{tabular}{ccccc}
\hline & $c_{1}$ & $c_{2}$ & $c_{3}$ & $c_{4}$ \\
\hline$A^{+}$ & $\{79(0.09), 62(0.28), 77(0.63)\}$ & $\{80(0.03), 68(0.29), 77(0.68)\}$ & $\{60(0.18), 73(0.21), 85(0.61)\}$ & $\{80(0.04), 88(0.36), 77(0.60)\}$ \\
$A^{-}$ & $\{55(0.22), 73(0.27), 68(0.51)\}$ & $\{70(0.16), 66(0.39), 60(0.45)\}$ & $\{71(0.1), 68(0.21), 62(0.69)\}$ & $\{77(0.02), 72(0.32), 64(0.66)\}$ \\
\hline
\end{tabular}

TABle 20: Distances between the alternatives and the idea solution.

\begin{tabular}{ccccc}
\hline & $A_{1}$ & $A_{2}$ & $A_{3}$ & $A_{4}$ \\
\hline$D_{i}^{+}$ & 6.5980 & 0.0000 & 9.1503 & 8.5449 \\
$D_{i}^{-}$ & 0.0000 & 6.5980 & 4.0679 & 5.6463 \\
\hline
\end{tabular}

TABLE 21: The relative closeness coefficients.

\begin{tabular}{ccccc}
\hline & $A_{1}$ & $A_{2}$ & $A_{3}$ & $A_{4}$ \\
\hline$C_{i}^{*}$ & 0.00 & 1.00 & 0.31 & 0.40 \\
\hline
\end{tabular}

\subsection{Sensitivity Analysis Based on the Parameter Values.} To better illustrate the advantages of the novel TODIM with probabilistic hesitant fuzzy information, this part conducts a sensitivity analysis of the novel TODIM and the extended TODIM with probabilistic hesitant fuzzy information and hesitant fuzzy information, respectively. Both comparative analyses fully illustrate the advantages of the novel TODIM based on PT. Moreover, this paper presents the comparative analysis to illustrate the superiority of probabilistic hesitant fuzzy information in reflecting more evaluation information of DMs by comparing it with hesitant fuzzy information in a fixed method.

5.2.1. Sensitivity Analysis of the Novel TODIM and the Extended TODIM with the Same Fuzzy Information. In the beginning, we analyze the difference of sensitivity between the novel TODIM and the extended TODIM with the same fuzzy information. According to the results, we recognize that no matter how the parameter $\lambda$ changes, there are no significant changes for the ranking results from each method. Therefore, we use the overall prospect dominance degrees to show the strength of the novel TODIM.

(1) Sensitivity Analysis of the Novel TODIM and the Extended TODIM with Probabilistic Hesitant Fuzzy Information. Since $\lambda$ is the only common parameter both in the novel TODIM and in the extended TODIM with probabilistic hesitant fuzzy information, the fluctuation of the overall prospect dominance degree can be easily observed by changing the value of $\lambda(1.25 \leq \lambda \leq 2.25)$ which is shown in Figure 2 .

The overall prospect dominance degrees of the first and the last alternative remain unchanged which is naturally determined by the TODIM itself, and they are 1 and 0 separately when the ranking result is unchanged. Subsequently, making the alternatives $A_{3}$ and $A_{4}$ as an analysis group, when $\lambda$ varies, the fluctuation range of the overall prospect dominance degree from the novel TODIM is smaller than the one obtained from the extended TODIM, which indicates that the novel TODIM is stable. Besides, the overall prospect dominance value obtained from the two methods shows a reverse trend. The main reason is that $\lambda$ is proportional to the dominance function in the novel TODIM, and it is also proportional to the overall prospect dominance degree. In the extended TODIM, the dominance function is affected by the reciprocal form of $\lambda$, so $\lambda$ is inversely proportional to the dominant function. This kind of reverse trend also can be found in the following analysis under the hesitant fuzzy environment. 


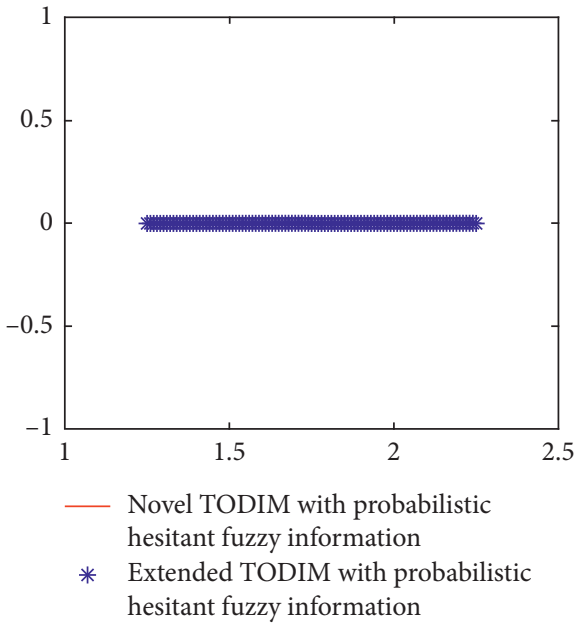

(a)

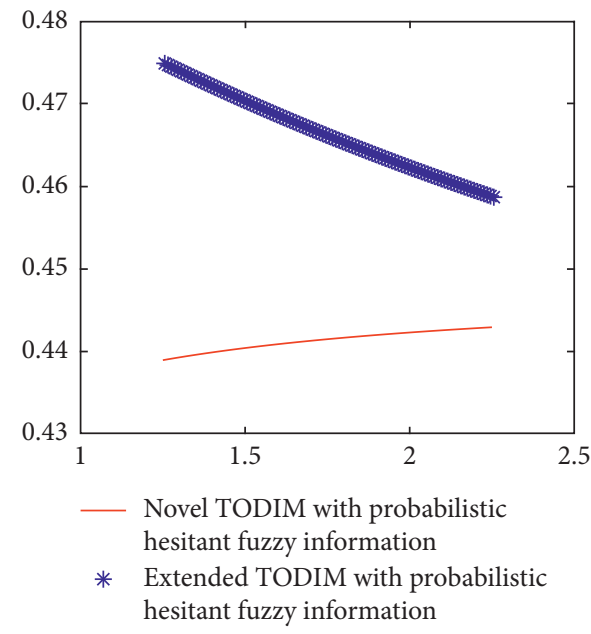

(c)

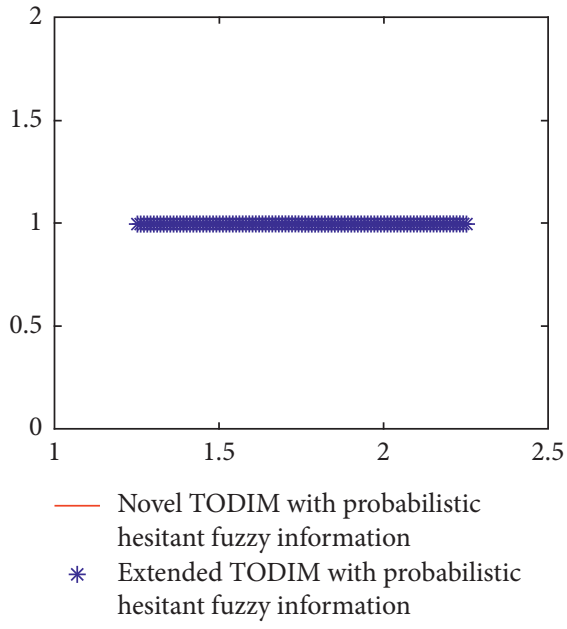

(b)

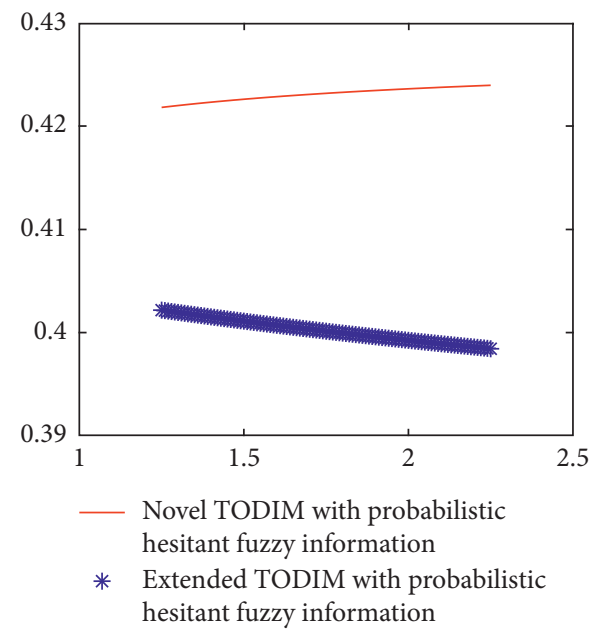

(d)

Figure 2: Sensitivity analysis with probabilistic hesitant fuzzy information. $1.25 \leq \lambda \leq 2.25, \alpha=\beta=0.88, \delta=0.69$, and $\gamma=0.61$. (a) $A_{1}$; (b) $A_{2} ;$ (c) $A_{3} ;$ (d) $\mathrm{A}_{4}$.

(2) Sensitivity Analysis of the Novel TODIM and the Extended TODIM with Hesitant Fuzzy Information. The changes of the overall prospect dominance degree in Figure 3 are obtained by altering the value of $\lambda(1.25 \leq \lambda \leq 2.25)$ in the novel TODIM and the extended TODIM with hesitant fuzzy information. According to Figure 3, it is apparent that the overall prospect dominance degrees of the alternatives $A_{1}$ and $A_{2}$ stay constant when the parameter $\lambda$ varies. At the same time, the fluctuation of the overall prospect dominance degree from the novel TODIM is smaller than that from the extended TODIM which also demonstrates that the novel TODIM is stable.

5.2.2. Sensitivity Analysis of the Novel TODIM and the Extended TODIM Based on Different Types of Fuzzy Information. This section presents two sets of comparative analyses to illustrate the advantages of probabilistic hesitant fuzzy information in expressing the perceptions of the DMs. The first one is the novel TODIM with probabilistic hesitant fuzzy information and with hesitant fuzzy information. The second one is the extended TODIM with probabilistic hesitant fuzzy information and with hesitant fuzzy information. We find that the ranking results of each alternative keep unchanged when the parameters change. Subsequently, the overall prospect dominance degrees are used to show the advantages of probabilistic hesitant fuzzy information.

(1) Sensitivity Analysis of the Novel TODIM with Probabilistic Hesitant Fuzzy Information and Compared with Hesitant Fuzzy Information. Since many parameters are used in the novel TODIM, this part presents the changes of overall prospect dominance degree of each alternative when the parameters change, which are shown in Figures 4-8.

Figure 4 presents the fluctuation of the overall prospect dominance degree from the novel TODIM with probabilistic hesitant fuzzy information and with hesitant fuzzy information separately by changing the parameter $\lambda$ $(1.25 \leq \lambda \leq 2.25)$. We can clearly see that for the alternatives $A_{3}$ and $A_{4}$, the changes of overall prospect dominance degree obtained by probabilistic hesitant fuzzy information are smaller than the one obtained by hesitant fuzzy 


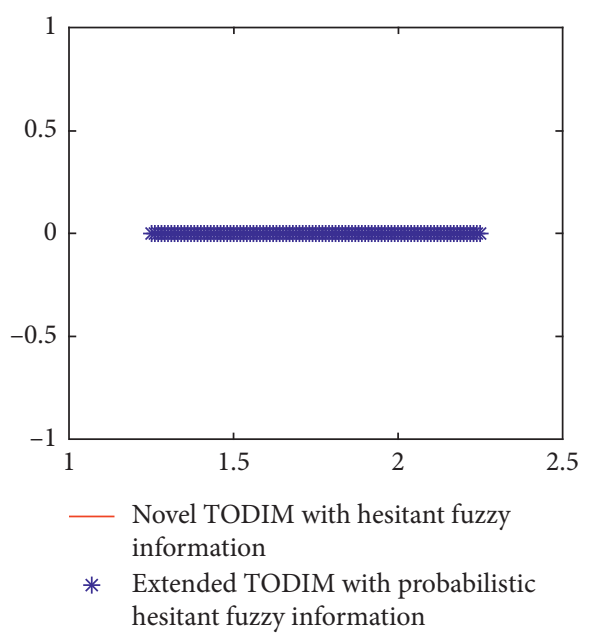

(a)

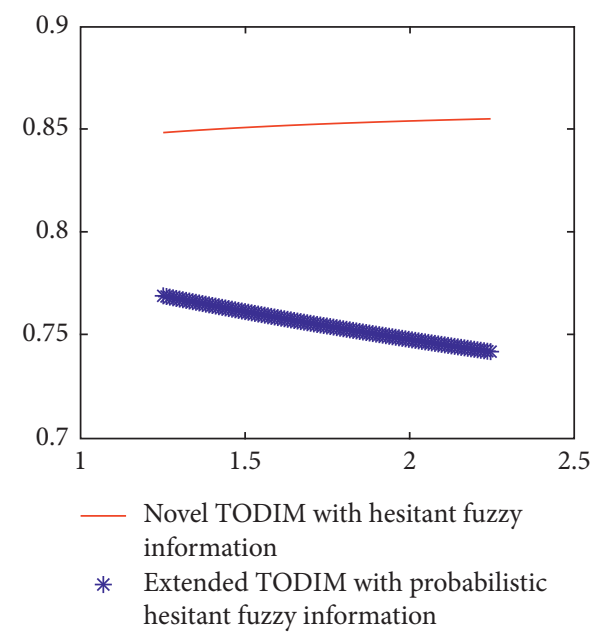

(c)

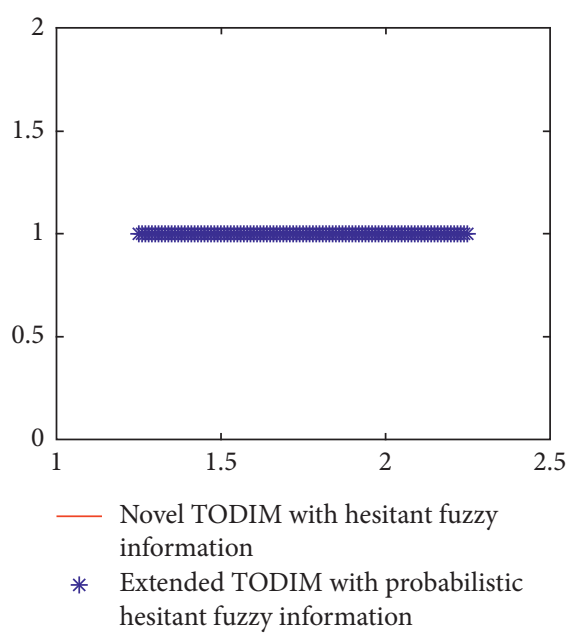

(b)

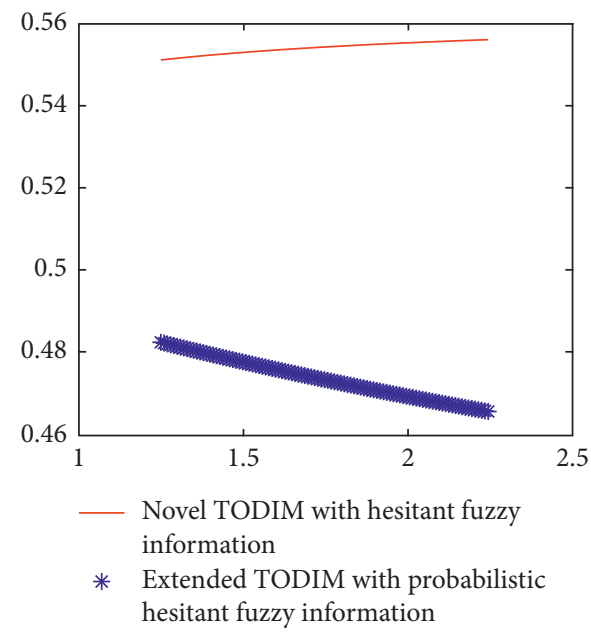

(d)

FIgURE 3: Sensitivity analysis with hesitant fuzzy information. $1.25 \leq \lambda \leq 2.25, \alpha=\beta=0.88, \delta=0.69$, and $\gamma=0.61$. (a) $A_{1}$; (b) $A_{2}$; (c) $A_{3}$; (d) $A_{4}$.

information, which indicates the stability of probabilistic hesitant fuzzy information.

Figure 5 presents the fluctuation of the overall prospect dominance degree from the novel TODIM with probabilistic hesitant fuzzy information and with hesitant fuzzy information separately by changing the parameter $\alpha$ $(0.68 \leq \alpha \leq 1.21)$. It is obvious that for the alternatives $A_{3}$ and $A_{4}$, the changes of overall prospect dominance degree obtained by probabilistic hesitant fuzzy information are smaller than the one obtained by hesitant fuzzy information, which also indicates that the probabilistic hesitant fuzzy information is stable.

Figure 6 presents the fluctuation of the overall prospect dominance degree from the novel TODIM with probabilistic hesitant fuzzy information and with hesitant fuzzy information separately by changing the parameter $\beta$ $(0.68 \leq \beta \leq 1.02)$. We can see that for the alternatives $A_{3}$ and $A_{4}$, the changes of overall prospect dominance degree obtained by probabilistic hesitant fuzzy information and by hesitant fuzzy information have obvious differences. For the alternative $A_{4}$, the change trend of the methods with two different types of information goes in the same direction; however, the greater fluctuation occurs in the method with hesitant fuzzy information. For the alternative $A_{3}$, the change trend of the two methods goes in the opposite direction.

Figure 7 presents the fluctuation of the overall prospect dominance degree from the novel TODIM with probabilistic hesitant fuzzy information and with hesitant fuzzy information separately by changing the parameter $\delta$ $(0.36 \leq \delta \leq 0.84)$. For the alternatives $A_{3}$ and $A_{4}$, significant fluctuation can be observed in the overall prospect dominance degree which is obtained by probabilistic hesitant fuzzy information, while small changes happen to the one obtained from hesitant fuzzy information. For both the alternatives $A_{3}$ and $A_{4}$, the overall prospect dominance degrees obtained from the two methods tend to change in the same direction.

Figure 8 presents the fluctuation of the overall prospect dominance degree obtained from the novel TODIM with 


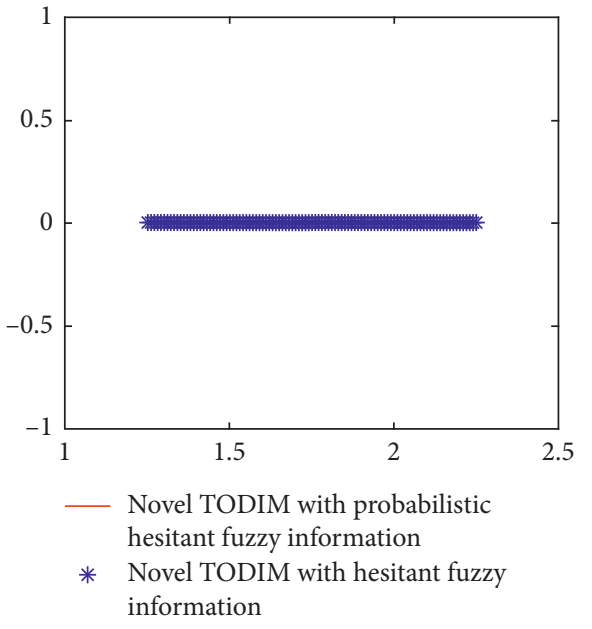

(a)

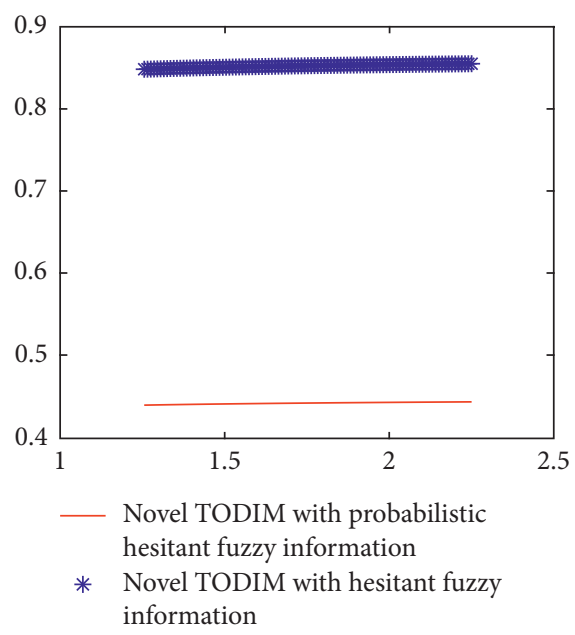

(c)

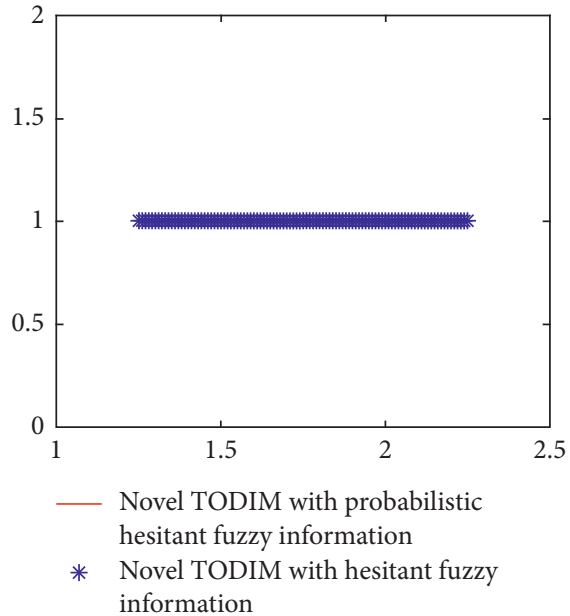

(b)

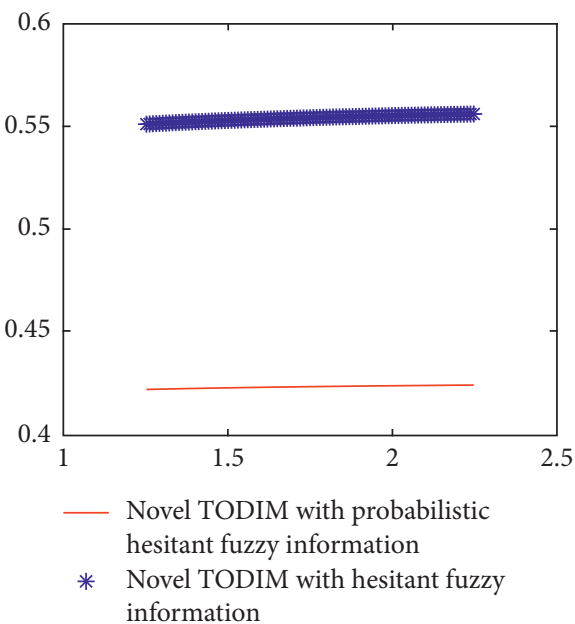

(d)

Figure 4: Sensitivity analysis of the novel TODIM by changing $\lambda .1 .25 \leq \lambda \leq 2.25, \alpha=\beta=0.88, \delta=0.69$, and $\gamma=0.61$. (a) $A_{1}$; (b) $A_{2}$; (c) $A_{3}$; (d) $A_{4}$.

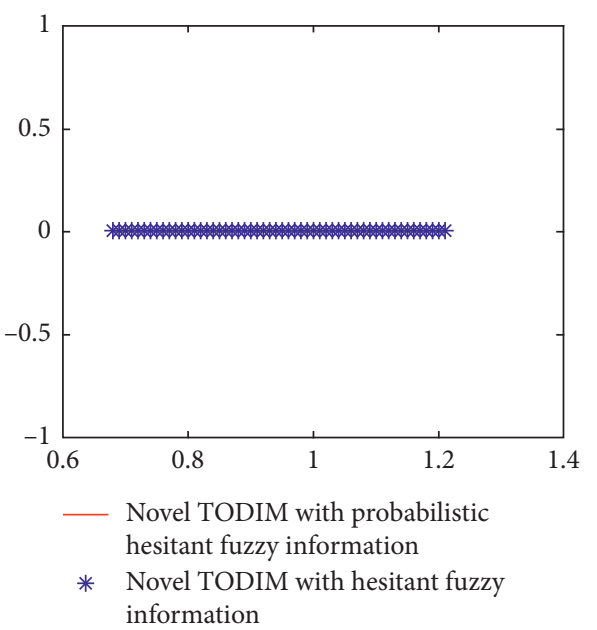

(a)

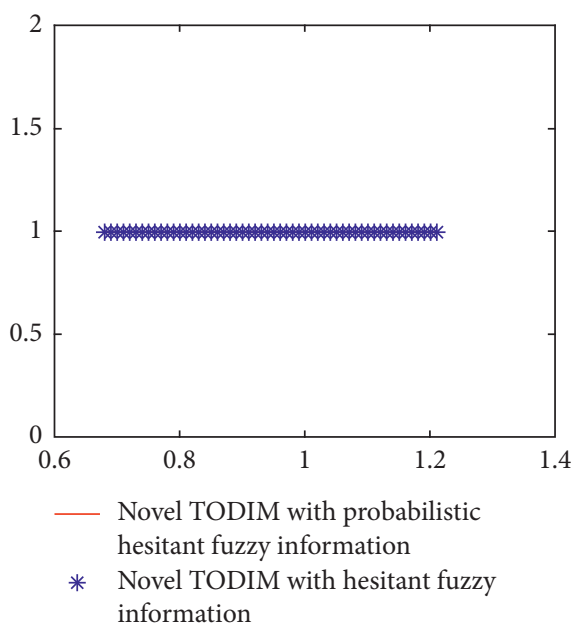

(b)

FIgURE 5: Continued. 


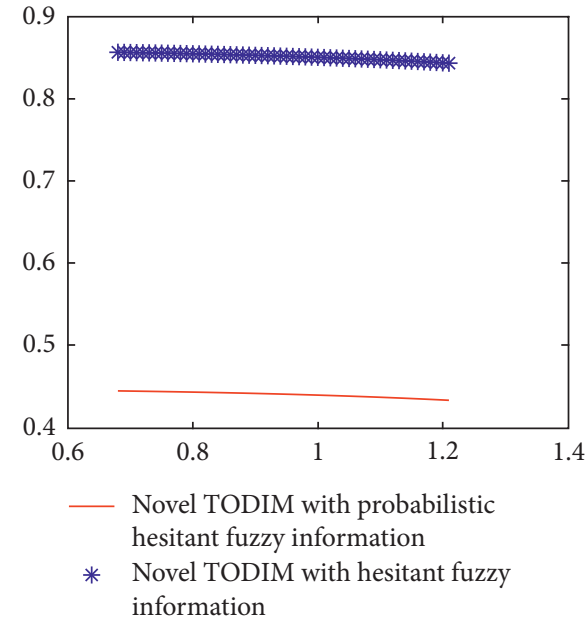

(c)

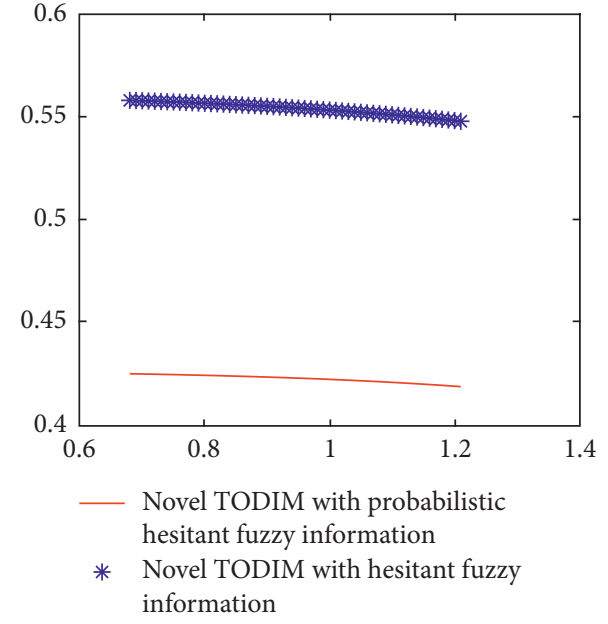

(d)

FIGURE 5: Sensitivity analysis of novel TODIM by changing $\alpha .0 .68 \leq \alpha \leq 1.21, \beta=0.88, \delta=0.69, \gamma=0.61$, and $\lambda=2.25$. (a) $A_{1}$; (b) $A_{2}$; (c) $A_{3}$; (d) $A_{4}$.

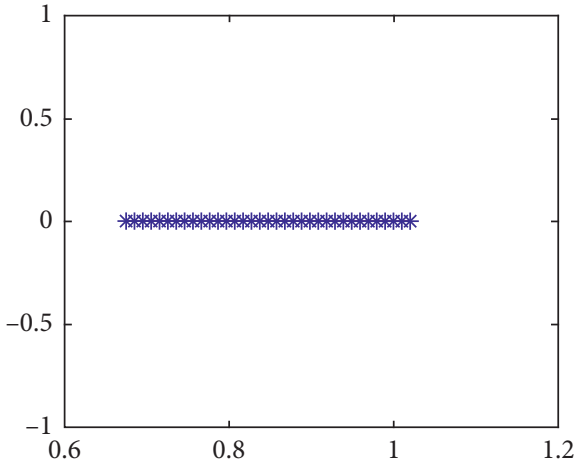

— Novel TODIM with probabilistic hesitant fuzzy information

* Novel TODIM with hesitant fuzzy information

(a)

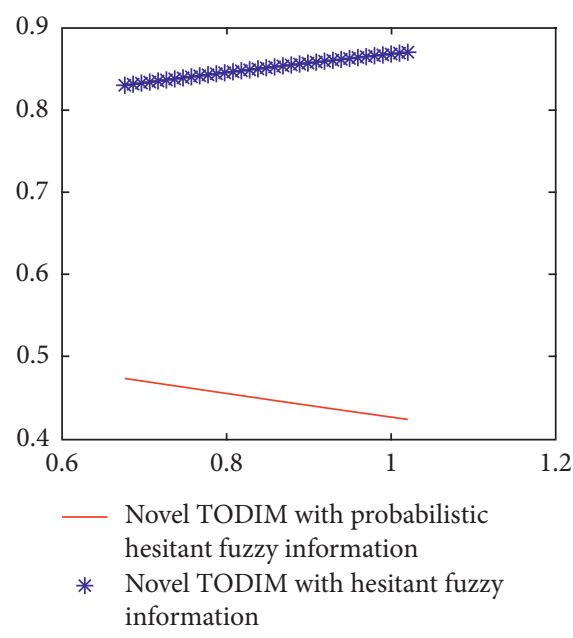

(c)

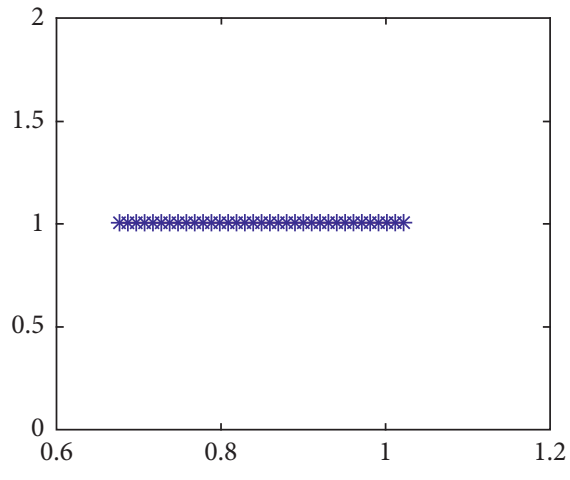

Novel TODIM with probabilistic hesitant fuzzy information

* Novel TODIM with hesitant fuzzy information

(b)

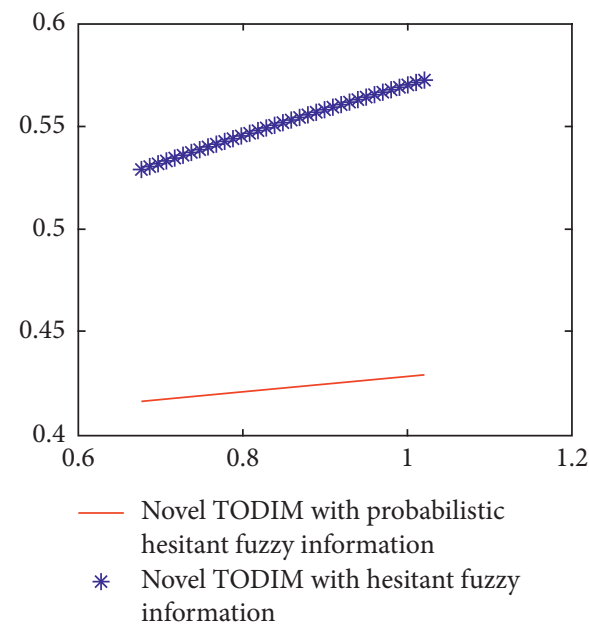

(d)

Figure 6: Sensitivity analysis of novel TODIM by changing $\beta .0 .68 \leq \beta \leq 1.02, \alpha=0.88, \delta=0.69, \gamma=0.61$, and $\lambda=2.25$. (a) $A_{1}$; (b) $A_{2}$; (c) $A_{3}$; (d) $A_{4}$. 


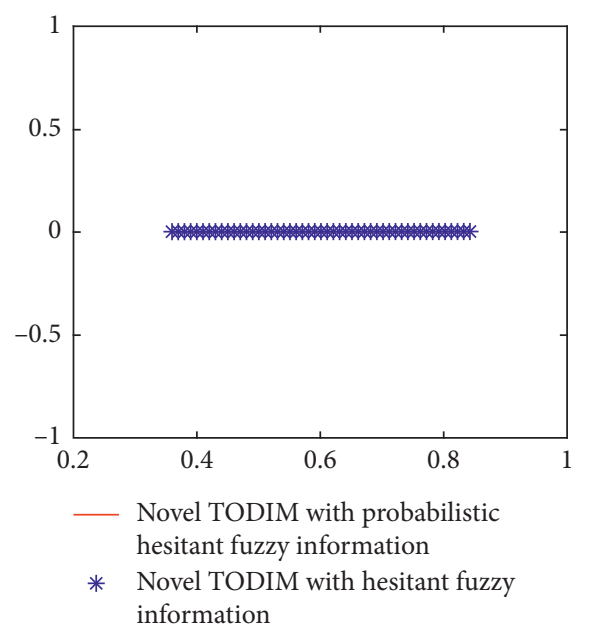

(a)

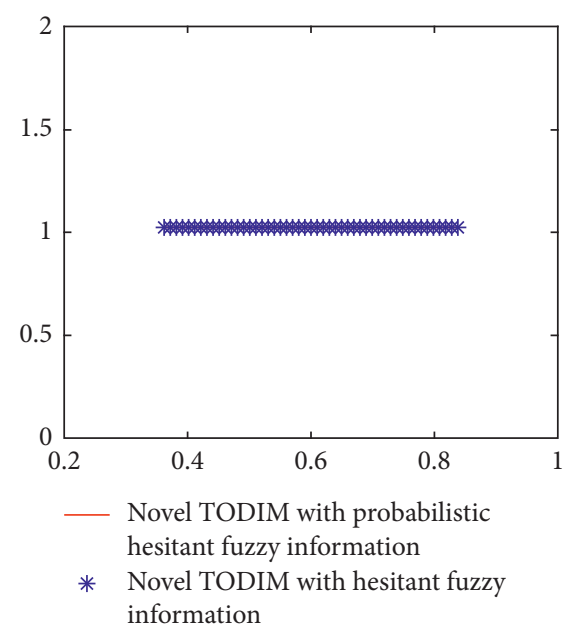

(b)

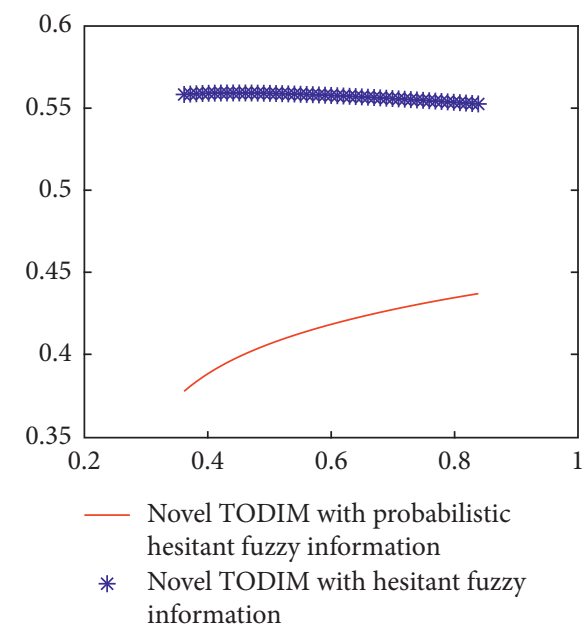

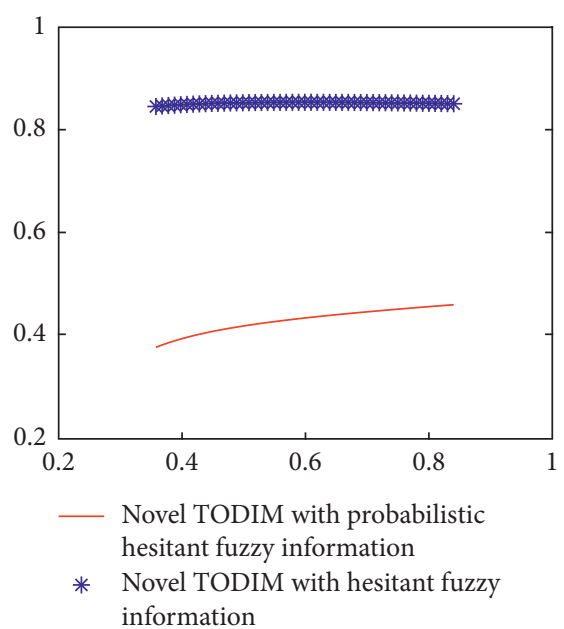

(c)

(d)

FIGURE 7: Sensitivity analysis of the novel TODIM by changing $\delta .0 .36 \leq \delta \leq 0.84, \alpha=\beta=0.88, \gamma=0.61$, and $\lambda=2.25$. (a) $A_{1}$; (b) $A_{2}$; (c) $A_{3}$; (d) $A_{4}$.

probabilistic hesitant fuzzy information and with hesitant fuzzy information separately by changing the parameter $\gamma$ $(0.55 \leq \gamma \leq 0.721)$. For the alternatives $A_{3}$ and $A_{4}$, the overall prospect dominance degrees obtained from these two kinds of methods are almost unchanged. No matter how $A_{3}$ or $A_{4}$ alters, the overall prospects tend to change in the same direction.

(2) Sensitivity Analysis of the Extended TODIM with Probabilistic Hesitant Fuzzy Information and Compared with Hesitant Fuzzy Information. Since there is only one mutual parameter $\lambda$ in the extended TODIM, this section considers the changes of the overall prospect dominance degree by changing it.

Figure 9 presents the fluctuation of the overall prospect dominance degree by changing the parameter $\lambda$
$(1.25 \leq \lambda \leq 2.25)$ in the extended TODIM with probabilistic hesitant fuzzy information and with hesitant fuzzy information. For the alternatives $A_{3}$ and $A_{4}$, the overall prospect dominance degree obtained by hesitant fuzzy information changes significantly, while the one obtained by probabilistic hesitant fuzzy information is nearly unchanged, and it also continues to decrease when increasing the value of the parameter $\lambda$. Besides, regardless of the alternative $A_{3}$ or $A_{4}$, the overall prospect dominance degrees obtained from the two methods tend to change in the same direction.

In summary, the novel TODIM is stable and effective (Figures 2 and 3) with the same type of fuzzy information. The overall prospect dominance degree obtained by probabilistic hesitant fuzzy information changes slightly than the one obtained by hesitant fuzzy information (Figures 4 and 9). 


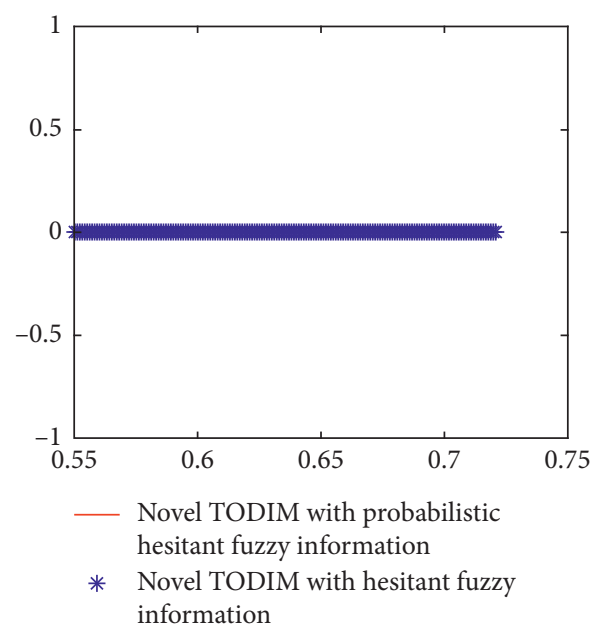

(a)

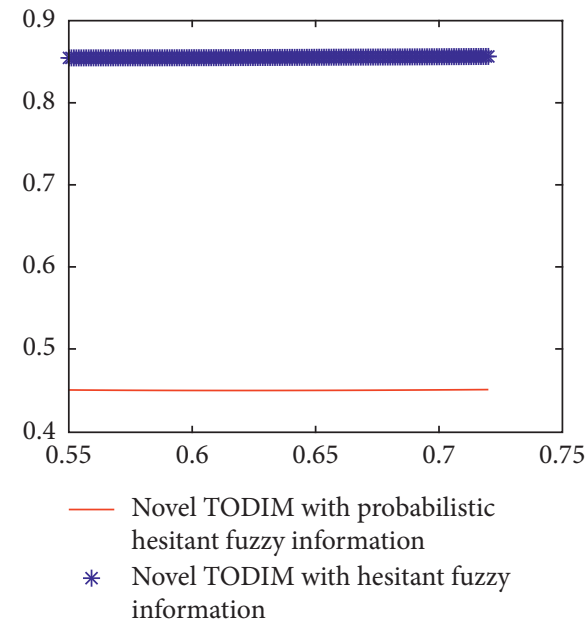

(c)

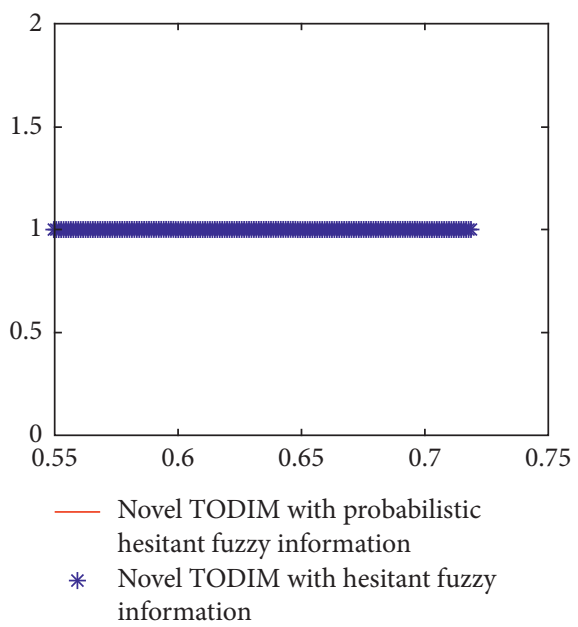

(b)

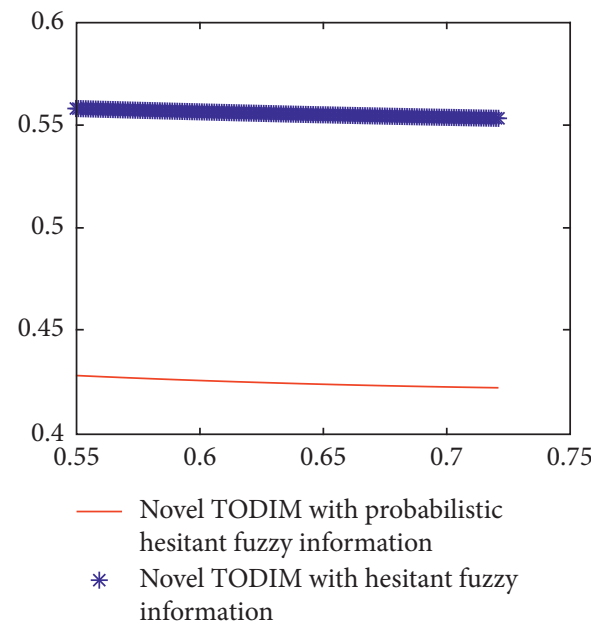

(d)

FIGURE 8: Sensitivity analysis of the novel TODIM by changing $\gamma \cdot 0.55 \leq \gamma \leq 0.721, \alpha=\beta=0.88, \delta=0.69$, and $\lambda=2.25$. (a) $A_{1}$; (b) $A_{2}$; (c) $A_{3}$; (d) $A_{4}$.

The results illustrate that the probabilistic hesitant fuzzy information is steadier and contains more information from DMs. Figures 5-9 present the changes in the overall prospect dominance degree when changing other parameters with different types of fuzzy information from the novel TODIM.

5.3. Simulation Analysis. After sensitivity analysis of the parameters based on one sample, we present the analysis results of 1000 sets of data which are randomly generated by MATLAB software. The ranking results are shown in Table 22 and Figures 10-13.

From Table 22, the ranking results of 1000 sets of random data by using different kinds of methods are presented. 393 sets of data have the same ranking results in these four methods. With probabilistic hesitant fuzzy information, 633 sets of data have the same ranking results by using the novel TODIM and the extended TODIM. However, with hesitant fuzzy information, 654 sets of data are observed to have the same ranking results by using the novel TODIM and the extended TODIM. The number of ranking results with hesitant fuzzy information is bigger than that of the ranking results with probabilistic hesitant fuzzy information because the latter one includes more information and it is more difficult to get the same ranking result. 622 sets of data have the same ranking results by using the novel TODIM with probabilistic hesitant fuzzy information and the novel TODIM with hesitant fuzzy information. 679 sets of data have the same ranking results by using the extended TODIM with probabilistic hesitant fuzzy information and the extended TODIM with hesitant fuzzy information.

According to the results, there are large numbers of random data with the same ranking results, which shows the feasibility and applicability of the proposed method. On 


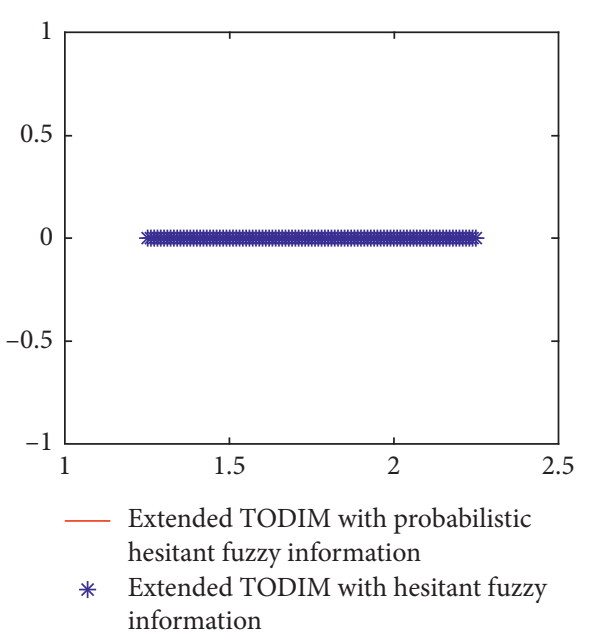

(a)

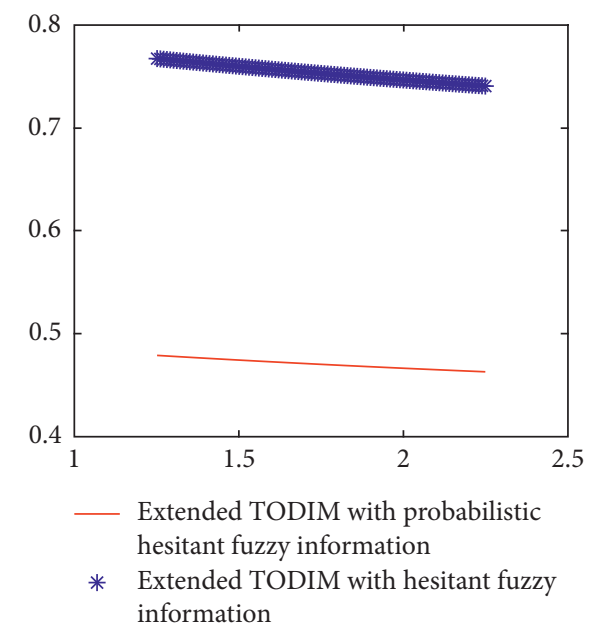

(c)

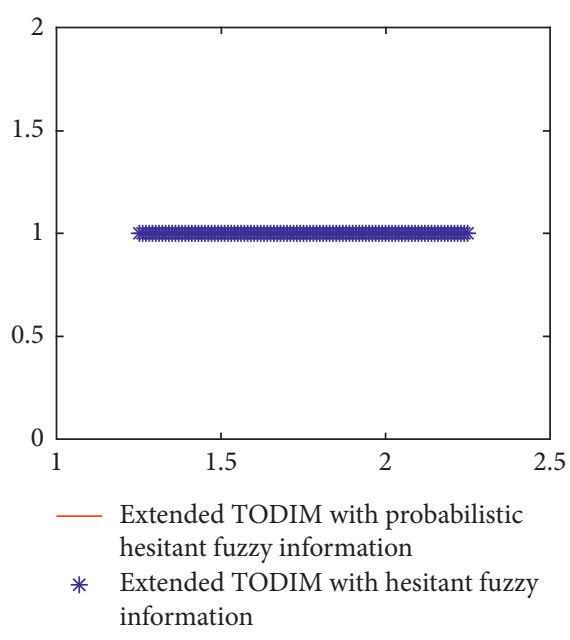

(b)

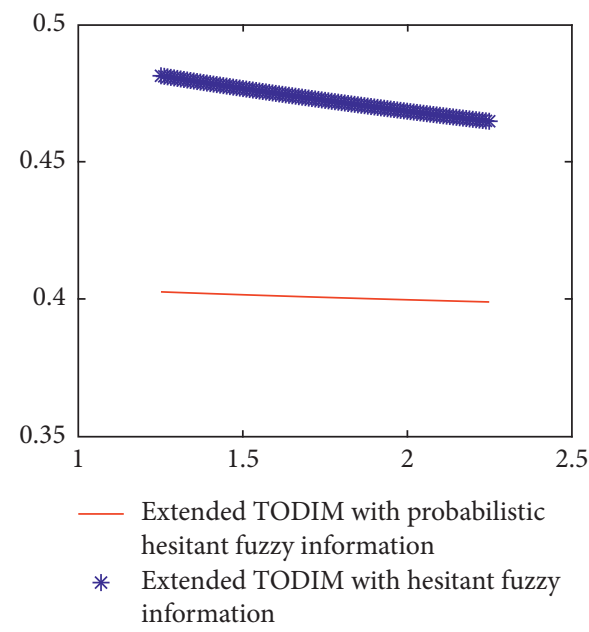

(d)

FIgURE 9: Sensitivity analysis of extended TODIM by changing $\lambda .1 .25 \leq \lambda \leq 2.25, \alpha=\beta=0.88, \gamma=0.61$, and $\delta=0.69$. (a) $A_{1}$; (b) $A_{2}$; (c) $A_{3}$; (d) $A_{4}$.

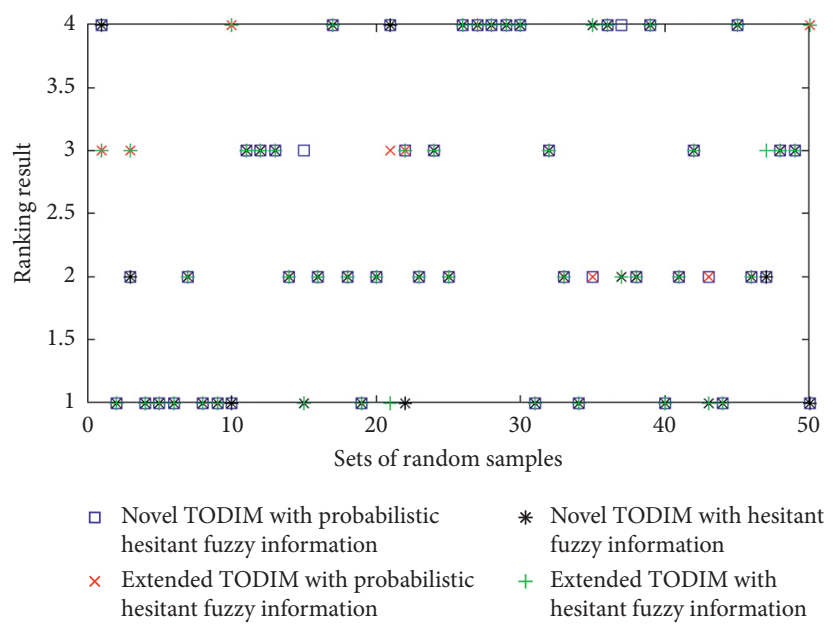

FIGURE 10: Ranking results of the alternative $A_{1}$ (50 sets of random samples). 
TABLE 22: Ranking results of each method with 1000 sets of random samples.

Methods

Novel TODIM with probabilistic hesitant fuzzy

information

Extended TODIM with probabilistic hesitant fuzzy

information

Novel TODIM with hesitant fuzzy information

Extended TODIM with hesitant fuzzy information

Novel TODIM with probabilistic hesitant fuzzy

information

Extended TODIM with probabilistic hesitant fuzzy

information

Novel TODIM with hesitant fuzzy information

Extended TODIM with hesitant fuzzy information

Novel TODIM with probabilistic hesitant fuzzy

information

Novel TODIM with hesitant fuzzy information

Extended TODIM with probabilistic hesitant fuzzy

information

Extended TODIM with hesitant fuzzy information

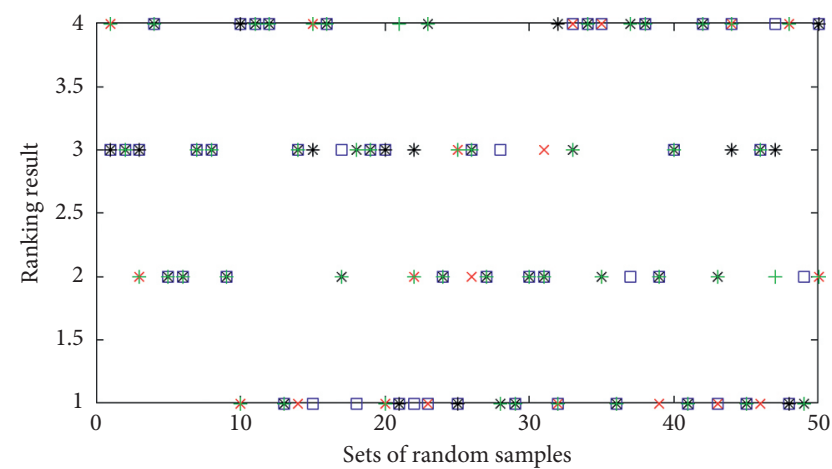

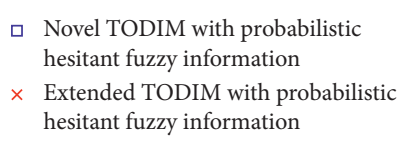

* Novel TODIM with hesitant fuzzy information

+ Extended TODIM with hesitant fuzzy information
FIGURE 11: Ranking results of the alternative $A_{2}$ (50 sets of random samples).

the contrary, there are still some existing sets of data samples with different ranking results which indicates the differences between these methods. We attribute this difference to the following two points: (1) Compared with hesitant fuzzy information, probabilistic hesitant fuzzy information contains more original decision information. The former one is just a special form of probabilistic hesitant fuzzy information when the probability is equal, and the latter one is more general. (2) Compared with the
Results

The number of the same ranking The number of the different ranking result result

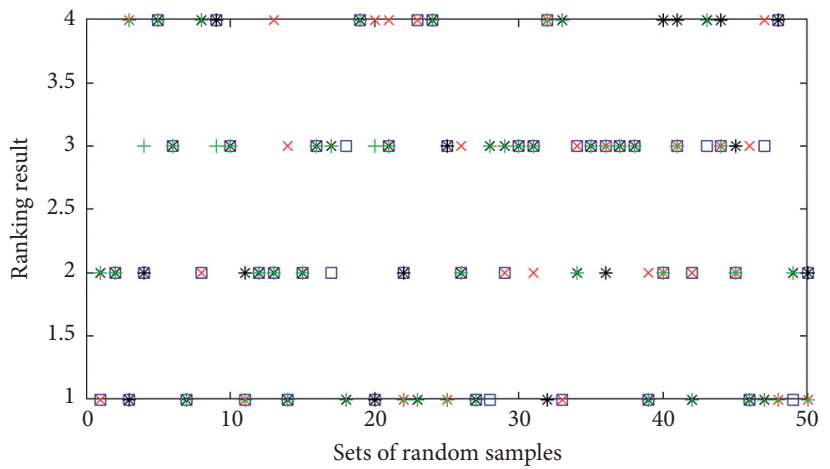

$\square$ Novel TODIM with probabilistic hesitant fuzzy information

$\times$ Extended TODIM with probabilistic

hesitant fuzzy information
* Novel TODIM with hesitant fuzzy information

+ Extended TODIM with hesitant fuzzy information
FIGURE 12: Ranking results of the alternative $A_{3}$ (50 sets of random samples).

extended TODIM, the novel TODIM based on PT rewrites the dominance function of TODIM and makes it more in line with the actual decision-making environment, which contains more details about risk attitudes for gains and losses of DMs. Based on Table 22, the ranking results are presented in the form of numbers. To observe the ranking results of each alternative more intuitively, Figures 10-13 present the ranking results of the first 50 sets of random data in detail. 


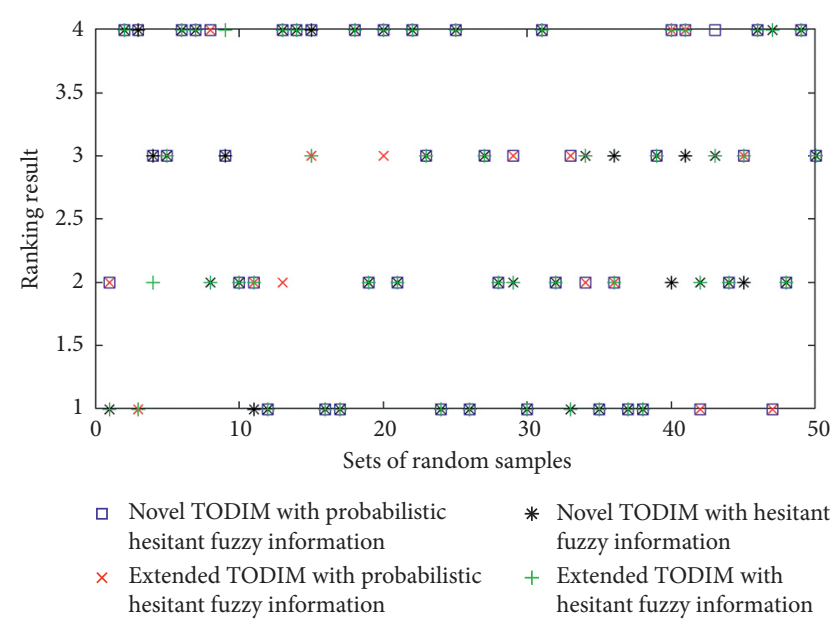

FIGURE 13: Ranking results of the alternative $A_{4}$ (50 sets of random samples).

\section{Conclusions}

The TODIM is a MCDM method based on PT which shows the risk aversion attitude through the dominance function. Based on equation (6) of the classical TODIM, the relative weight is calculated by the one-dimensional probability weight; however, according to equation (3), the original PT considers that the DMs adopt the nonlinear transformed probability weight function in the decision-making process. Without a doubt, the classical TODIM ignores the effect of the transformed probability weighting function on decisionmaking results. Besides, it is easy to recognize from equation (8) that the multiply value of relative probability weight and the perceived gain or loss value are regarded as the overall preferences of the DMs in the classic TODIM. However, the different risk attitudes for gains and losses are mainly reflected by the value function in the classic PT according to equation (2), and it takes the product of the value function and the weight function as a decision reference. Such a phenomenon has not been well proclaimed in the classical TODIM.

At the same time, it is considered that the DMs are more likely to express their perceptions as the form of probabilistic hesitant fuzzy information under the highly uncertain circumstance because they can express their preference for the hesitant fuzzy values by probabilistic hesitant fuzzy information. That is the reason why we propose a probabilistic hesitant fuzzy TODIM based on a new perspective of PT. To illustrate the feasibility and effectiveness of the proposed method, this paper also presents the novel TODIM with hesitant fuzzy information and TOPSIS with probabilistic hesitant fuzzy information.

The most important innovation of this paper is that an improved TODIM based on PT with probabilistic hesitant fuzzy information is proposed. This paper realizes the reconstruction of the relative dominance function of the classical TODIM based on PT and integrates probabilistic hesitant fuzzy information into the improved TODIM. Moreover, this paper combines the novel TODIM with the hesitant fuzzy information. Furthermore, a case study, parameter sensitivity analysis, and simulation analysis are all carried out to show the advantages of the proposed methods and the differences between these methods and the existing ones.

The proposed method has some certain advantages in expressing fuzzy information of the DMs. For example, probabilistic hesitant fuzzy information can express the degree of hesitation by using different probabilities for hesitant values. On the contrary, probability can also represent the proportion that the DMs give the same hesitation value in group decision-making. There is no doubt that group decision-making has become an effective way to solve complicated problems and consensus is the precondition to make a reasonable decision. Hence, more concentration should be put into consensus problems based on PT in the future.

\section{Data Availability}

The data used to support the findings of this study are available from the corresponding author upon request.

\section{Conflicts of Interest}

The authors declare that they have no conflicts of interest.

\section{Acknowledgments}

This research was funded by the National Natural Science Foundation of China (No. 71771155) and also supported by the Fundamental Research Funds for the Central Universities (No. JBK2001043).

\section{References}

[1] S.-P. Wan, W. Zou, and J.-Y. Dong, "Prospect theory based method for heterogeneous group decision making with hybrid truth degrees of alternative comparisons," Computers \& Industrial Engineering, vol. 141, p. 106285, 2020.

[2] L. F. A. M. Gomes and M. M. P. P. Lima, "TODIM: basic and application to multicriteria ranking of projects with environmental impacts," Fund Computing Decision Science, vol. 16, no. 4, pp. 113-127, 1991.

[3] Z.-P. Fan, X. Zhang, F.-D. Chen, and Y. Liu, "Extended TODIM method for hybrid multiple attribute decision making problems," Knowledge-Based Systems, vol. 42, pp. 40-48, 2013.

[4] R. Lourenzutti, R. A. Krohling, and M. Z. Reformat, "Choquet based TOPSIS and TODIM for dynamic and heterogeneous decision making with criteria interaction," Information Sciences, vol. 408, pp. 41-69, 2017.

[5] R. Lourenzutti and R. A. Krohling, "A study of TODIM in a intuitionistic fuzzy and random environment," Expert Systems with Applications, vol. 40, no. 16, pp. 6459-6468, 2013.

[6] P. Ren, Z. Xu, and X. Gou, "Pythagorean fuzzy TODIM approach to multi-criteria decision making," Applied Soft Computing, vol. 42, pp. 246-259, 2016.

[7] X. Peng and J. Dai, "Approaches to Pythagorean fuzzy stochastic multi-criteria decision making based on prospect theory and regret theory with new distance measure and score 
function," International Journal of Intelligent Systems, vol. 32, no. 11, pp. 1187-1214, 2017.

[8] X. Tian, M. Niu, W. Zhang, L. Li, and E. Herrera-Viedma, “A novel TODIM based on prospect theory to select green supplier with q-rung orthopair fuzzy set," Technological and Economic Development of Economy, p. 1, 2020.

[9] R. A. Krohling and T. T. M. de Souza, "Combining prospect theory and fuzzy numbers to multi-criteria decision making," Expert Systems with Applications, vol. 39, no. 13, pp. 1148711493, 2012.

[10] R. A. Krohling, A. G. C. Pacheco, and A. L. T. Siviero, "IFTODIM: an intuitionistic fuzzy TODIM to multi-criteria decision making," Knowledge-Based Systems, vol. 53, pp. 142-146, 2013.

[11] G. Zhang, J. q. Wang, and T. 1. Wang, "Multi-criteria group decision-making method based on TODIM with probabilistic interval-valued hesitant fuzzy information," Expert Systems, vol. 36, no. 4, 2019.

[12] J. J. Peng, J. Q. Wang, H. Zhou, and X. H. Chen, "A multicriteria decision-making approach based on TODIM and Choquet integral within a multiset hesitant fuzzy environment," Applied Mathematics and Information Sciences, vol. 9, no. 4, pp. 2087-2097, 2015.

[13] Z. L. Ren, Z. S. Xu, and H. Wang, "An extended TODIM method under probabilistic dual hesitant fuzzy information and its application on enterprise strategic assessment," in Proceedings of the IEEE International Conference on Industrial Engineering and Engineering Management, pp. 1464-1468, Singapore, December 2017.

[14] X.-F. Ding, H.-C. Liu, and H. Shi, “A dynamic approach for emergency decision making based on prospect theory with interval-valued Pythagorean fuzzy linguistic variables," Computers \& Industrial Engineering, vol. 131, pp. 57-65, 2019.

[15] W. Yu, Z. Zhang, Q. Zhong, and L. Sun, "Extended TODIM for multi-criteria group decision making based on unbalanced hesitant fuzzy linguistic term sets," Computers \& Industrial Engineering, vol. 114, pp. 316-328, 2017.

[16] M. Zhang, P. Liu, and L. Shi, "An extended multiple attribute group decision-making TODIM method based on the neutrosophic numbers," Journal of Intelligent \& Fuzzy Systems, vol. 30, no. 3, pp. 1773-1781, 2016.

[17] J. Qin, X. Liu, and W. Pedrycz, "An extended TODIM multicriteria group decision making method for green supplier selection in interval type-2 fuzzy environment," European Journal of Operational Research, vol. 258, no. 2, pp. 626-638, 2017.

[18] X. Sang and X. Liu, "An interval type-2 fuzzy sets-based TODIM method and its application to green supplier selection," Journal of the Operational Research Society, vol. 67, no. 5, pp. 722-734, 2016.

[19] R. A. Krohling and A. G. C. Pacheco, "Interval-valued intuitionistic fuzzy TODIM," Procedia Computer Science, vol. 31, pp. 236-244, 2014.

[20] A. R. Mishra and P. Rani, "Biparametric information measures-based TODIM technique for interval-valued intuitionistic fuzzy environment," Arabian Journal for Science and Engineering, vol. 43, no. 6, pp. 3291-3309, 2018.

[21] Q. Qin, F. Liang, L. Li, Y.-W. Chen, and G.-F. Yu, “A TODIMbased multi-criteria group decision making with triangular intuitionistic fuzzy numbers," Applied Soft Computing, vol. 55, pp. 93-107, 2017.

[22] Y. N. Wu, J. Wang, Y. Hu, Y. M. Ke, and L. W. Y. Li, “An extended TODIM-PROMETHEE method for waste-to- energy plant site selection based on sustainability perspective," Energy, vol. 156, pp. 1-16, 2018.

[23] X. Zhang and Z. Xu, "The TODIM analysis approach based on novel measured functions under hesitant fuzzy environment," Knowledge-Based Systems, vol. 61, pp. 48-58, 2014.

[24] X. Zhang, "A closeness index-based TODIM method for hesitant qualitative group decision making," Informatica, vol. 28, no. 3, pp. 565-581, 2017.

[25] W. Zhang, J. Du, and X. Tian, "Finding a promising venture capital project with TODIM under probabilistic hesitant fuzzy circumstance," Technological and Economic Development of Economy, vol. 24, no. 5, pp. 2026-2044, 2018.

[26] S. Wang and J. Liu, "Extension of the TODIM method to intuitionistic linguistic multiple attribute decision making," Symmetry, vol. 9, no. 6, p. 95, 2017.

[27] C. Wei, Z. Ren, and R. M. Rodríguez, "A hesitant fuzzy linguistic TODIM method based on a score function," International Journal of Computational Intelligence Systems, vol. 8, no. 4, pp. 701-712, 2015.

[28] P. Li, X. Chen, X. Qu, and Q. Xu, “The evaluation of mineral resources development efficiency based on hesitant fuzzy linguistic approach and modified TODIM," Mathematical Problems in Engineering, vol. 2018, Article ID 1808426, 9 pages, 2018.

[29] J. Wang, J.-q. Wang, and H.-y. Zhang, "A likelihood-based TODIM approach based on multi-hesitant fuzzy linguistic information for evaluation in logistics outsourcing," Computers \& Industrial Engineering, vol. 99, pp. 287-299, 2016.

[30] R. Sun, J. Hu, and X. Chen, "Novel single-valued neutrosophic decision-making approaches based on prospect theory and their applications in physician selection," Soft Computing, vol. 23, no. 1, pp. 211-225, 2017.

[31] A. Tversky and D. Kahneman, "Advances in prospect theory: cumulative representation of uncertainty," Journal of Risk and Uncertainty, vol. 5, no. 4, pp. 297-323, 1992.

[32] X. Tian, Z. Xu, and J. Gu, "An extended TODIM based on cumulative prospect theory and its application in venture capital," Informatica, vol. 30, no. 2, pp. 413-429, 2019.

[33] Z.-P. Fan, X. Zhang, F.-D. Chen, and Y. Liu, "Multiple attribute decision making considering aspiration-levels: a method based on prospect theory," Computers \& Industrial Engineering, vol. 65, no. 2, pp. 341-350, 2013.

[34] V. Torra, "Hesitant fuzzy sets," International Journal of Intelligent Systems, vol. 25, no. 6, pp. 529-539, 2010.

[35] S. Zhang, Z. Xu, and Y. He, "Operations and integrations of probabilistic hesitant fuzzy information in decision making," Information Fusion, vol. 38, pp. 1-11, 2017.

[36] C. Tan, Z.-Z. Jiang, and X. Chen, "An extended TODIM method for hesitant fuzzy interactive multicriteria decision making based on generalized Choquet integral," Journal of Intelligent \& Fuzzy Systems, vol. 29, no. 1, pp. 293-305, 2015.

[37] J. Gao, Z. Xu, and H. Liao, "A dynamic reference point method for emergency response under hesitant probabilistic fuzzy environment," International Journal of Fuzzy Systems, vol. 19, no. 5, pp. 1261-1278, 2017.

[38] "The US has a Fleet of 300 Electric Buses. China Has 421,000", 2019, https://www.bloomberg.com.

[39] "Electric Buses are Hurting the Oil Industry", 2018, http://www. bloomberg.com.

[40] W. Zhang, X. Tian, and A. Yu, "Is high-speed rail a catalyst for the fourth industrial revolution in China? Story of enhanced technology spillovers from venture capital," Technological Forecasting and Social Change, vol. 161, p. 120286, 2020. 
[41] X. Tian, G. Kou, and W. Zhang, "Geographic distance, venture capital and technological performance: evidence from Chinese enterprises," Technological Forecasting and Social Change, vol. 158, Article ID 120155, 2020.

[42] Bid File of Shanghai Pudong New Area Public Transport Investment Development Company, http://www.ccgp.gov.cn/ cggg/dfgg/gkzb/201905/t20190531_12179251.htm.

[43] Y. He and Z. Xu, "Multi-attribute decision making methods based on reference ideal theory with probabilistic hesitant information," Expert Systems with Applications, vol. 118, pp. 459-469, 2019.

[44] M. Dagdeviren, S. Yavuz, and N. Kilinc, "Weapon selection using the AHP and TOPSIS methods under fuzzy environment," Expert Systems with Applications, vol. 36, no. 4, pp. 8143-8151, 2009. 